\title{
Damage Detection in Different Types of 3D Asymmetric Buildings Using Vibration Characteristics
}

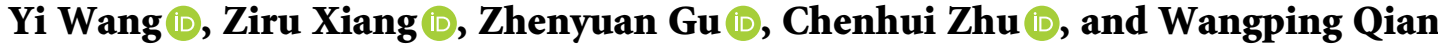 \\ School of Transportation and Civil Engineering, Nantong University, Nantong, China \\ Correspondence should be addressed to Zhenyuan Gu; guzhenyuan0507@ntu.edu.cn
}

Received 26 April 2021; Revised 16 August 2021; Accepted 14 September 2021; Published 25 September 2021

Academic Editor: Carlo Rainieri

Copyright (C) 2021 Yi Wang et al. This is an open access article distributed under the Creative Commons Attribution License, which permits unrestricted use, distribution, and reproduction in any medium, provided the original work is properly cited.

\begin{abstract}
This paper treats the vibration characteristics of three different types of asymmetric buildings and investigates the feasibility of applying an innovative vibration-based multicriteria approach-based damage index (MCA-DI) technique to detect the damage. This technique combines a modified form of the traditional modal strain energy method (MSEM) developed by decomposing the mode shapes into lateral and vertical components together with a modified form of the modal flexibility method to define a new damage indicator. Lastly, the dynamic behavior of three asymmetric building instances, including a 10-storey L-shaped structure, a 10-storey setback structure, and a 6-storey reinforced concrete structure with an unsymmetrical distribution of columns, was studied under five different damage scenarios. The results showed that despite different vibration characteristics of these three asymmetric buildings, the proposed method was able to accurately and effectively locate all damages and eliminate the confusion when more than one index is simultaneously used by using only the first a few modes.
\end{abstract}

\section{Introduction}

Advances in analytical techniques, modern construction technologies, and aesthetic needs have resulted in the massive construction of large-scale and complex building structures. Among them, asymmetric buildings make up the majority and exhibit complicated structural behavior. Asymmetry in buildings is represented by eccentricity in geometry, stiffness, or mass, which may have a large impact on the dynamic response of the building as torsion is generated under lateral loads [1]. The change in the dynamic response depends on the type of structural irregularity. Generally, structural irregularities can be classified into horizontal (unsymmetrical plan) and vertical irregularities (unsymmetrical elevation and unsymmetrical distribution of vertical members) [2]. Different types of asymmetries can result in significant differences in the dynamic response of asymmetric buildings and their vibration characteristics, which can pose a challenge in using the traditional vibrationbased methods to detect damage in them. There is thus a need for a simple and reliable procedure to detect and locate such damage in all types of asymmetric buildings, so that appropriate retrofitting can be carried out to prevent structural failure.

In general, damage of structures in the area of civil engineering was assessed by visual inspection (VI) techniques or Nondestructive Testing (NDT) techniques such as $\mathrm{X}$-ray and ultrasonic waves to measure cracks and permanent deformations [3]. Major drawbacks of these methods are that damaged regions are needed to be readily accessible and the collected data are insufficient to predict the remaining life of the structure. Aiming at addressing these drawbacks, methods such as Vibration-Based Damage Identification (VBDI) methods have been developed to effectively examine changes in structural vibration characteristics [4]. Under many circumstances, VBDI methods detect and locate damages solely by analyzing the measured and collected data such as natural frequencies and mode shapes in both the healthy and damaged structure or combining with structural numerical model results. Primordially, VBDI techniques have been applied in aircraft areas, railway systems, and other machinery [5]. In recent decades, it has been introduced into the field of civil engineering to identify structural damage. Generally, the 
performance of a damage indicator or a damage identification technique is decided by structural type [6]. Structures that received the greatest research interest include beams $[7,8]$, plate elements [9-11], trusses [12-14], steel frames $[15,16]$, offshore platforms [17-19], and bridges [20-22]. The applications in the above structures have indeed been successful in the last decades. However, it is still a challenge for civil engineers to identify the damage in complex structures such as $3 \mathrm{D}$ asymmetric buildings.

Studies on asymmetric buildings were mainly focused on seismic performance [23-27], modal identification $[28,29]$, and the effect of torsional coupling during an earthquake [30]. There have been fewer researches on damage identification of asymmetric buildings, and mostly on specific building types of asymmetric building. Omrani et al. [31] described a parameter estimation algorithm to identify the stiffness properties of torsionally coupled shear buildings; however, this method was only validated from the IASC-ASCE benchmark structure with stiffness eccentricity. Bernagozzi et al. [32] proposed a method using modal flexibility-based deflections also validated through structure with stiffness eccentricity. Kaloop and $\mathrm{Hu}$ [33] proposed a wavelet application for damage identification of asymmetric building with mass eccentricity. Wang et al. [34] investigated a new damage index to evaluate the storey damage of an L-shaped single storey building. Wang et al. [35] developed a Multicriteria Approach Based Damage Index (MCA-DI) to detect and locate damage in asymmetric buildings. However, this paper only considered buildings with mass eccentricity, which may not represent all types of asymmetric buildings. This paper, therefore, treats the damage detection in three typical types of asymmetric building structures, which are more complex and have strong irregularities in the plan and in the elevation using the proposed MCA-DI method, and more damage scenarios have been considered, the capability of the proposed method is tested with noise effect and incomplete mode shape, thereby establishes the capability of MCA-DI to detect damage in most asymmetric buildings.

\section{Theory}

2.1. Traditional Method. Traditional modal strain energy (MSE) method was developed by Stubbs and Kim [36] as follows:

$$
\beta_{j}=\frac{\sum_{i=1}^{N_{m}}\left\{\left(\left(\boldsymbol{\varphi}_{i}^{d}\right)^{T} \mathbf{K}_{j 0} \boldsymbol{\varphi}_{i}^{d}+\left(\boldsymbol{\varphi}_{i}^{d}\right)^{T} \mathbf{K}_{0} \boldsymbol{\varphi}_{i}^{d}\right)\left(\boldsymbol{\varphi}_{i}\right)^{T} \mathbf{K} \boldsymbol{\varphi}_{i}\right\}}{\sum_{i=1}^{N_{m}}\left\{\left(\left(\boldsymbol{\varphi}_{i}\right)^{T} \mathbf{K}_{j 0} \boldsymbol{\varphi}_{i}+\left(\boldsymbol{\varphi}_{i}\right)^{T} \mathbf{K}_{0} \boldsymbol{\varphi}_{i}\right)\left(\boldsymbol{\varphi}_{i}^{d}\right)^{T} \mathbf{K} \boldsymbol{\varphi}_{i}^{d}\right\}},
$$

where $\mathbf{K}$ represent the set of all element stiffness matrices, $\mathbf{K}_{0}, \mathbf{K}_{j 0}$ are the matrices with geometric quantities only; $\varphi_{i}$, $\varphi_{i}^{d}$ represent the $i$ th intact and damaged mode shape, respectively, the superscript $T$ is the transpose operator, $N_{m}$ is the number of modes being considered. All the mode shapes used in this study are mass-normalized mode shapes. For numerical example, it is obtained from the modal analysis directly. For the experimental study, it is calculated by the method proposed by López-Aenlle et al. [37].
Suppose $\mathrm{mse}_{j}$ as the normalized indicator for a more robust damage detection criterion, and it can be written as equation (2), where $\bar{\beta}, \sigma_{\beta}$ represent the mean value and standard deviation of damage localization indicator $\beta$, respectively.

$$
\mathrm{mse}_{j}=\frac{\beta_{j}-\bar{\beta}}{\sigma_{\beta}} .
$$

2.2. Modified Method. The research presented by Wang et al. [35] showed that the damage in a beam element leans to affect the connected other beam elements on account of torsional coupling. Equal feature occurs conspicuously in columns for an asymmetric building. This tendency differs from that in symmetric buildings. For the most part, there are two types of elements for the members of an asymmetric frame structure, that is, beam members and column members. Normally structural vibration modes for the buildings are concentrated horizontally, in which case the lateral MSE dominates the change of MSE in the column members. On the contrary, the vertical MSE contributes significantly to the change of MSE in the beam members [38]. The modified damage indices, that is, a lateral damage index and a vertical damage index [39], are obtained from the decomposing of Stubbs' damage index.

$$
\beta_{j}^{L}=\frac{\sum_{i=1}^{N_{m}}\left\{\left(\left(\boldsymbol{\varphi}_{i}^{L d}\right)^{T} \mathbf{K}_{j 0} \boldsymbol{\varphi}_{i}^{L d}+\left(\boldsymbol{\varphi}_{i}^{L d}\right)^{T} \mathbf{K}_{0} \boldsymbol{\varphi}_{i}^{L d}\right)\left(\boldsymbol{\varphi}_{i}^{L}\right)^{T} \mathbf{K} \boldsymbol{\varphi}_{i}^{L}\right\}}{\sum_{i=1}^{N_{m}}\left\{\left(\left(\boldsymbol{\varphi}_{i}^{L}\right)^{T} \mathbf{K}_{j 0} \boldsymbol{\varphi}_{i}^{L}+\left(\boldsymbol{\varphi}_{i}^{L}\right)^{T} \mathbf{K}_{0} \boldsymbol{\varphi}_{i}^{L}\right)\left(\boldsymbol{\varphi}_{i}^{L d}\right)^{T} \mathbf{K} \boldsymbol{\varphi}_{i}^{L d}\right\}},
$$

$$
\beta_{j}^{V}=\frac{\sum_{i=1}^{N_{m}}\left\{\left(\left(\boldsymbol{\varphi}_{i}^{V d}\right)^{T} \mathbf{K}_{j 0} \boldsymbol{\varphi}_{i}^{V d}+\left(\boldsymbol{\varphi}_{i}^{V d}\right)^{T} \mathbf{K}_{0} \boldsymbol{\varphi}_{i}^{V d}\right)\left(\boldsymbol{\varphi}_{i}^{V}\right)^{T} \mathbf{K} \boldsymbol{\varphi}_{i}^{V}\right\}}{\sum_{i=1}^{N_{m}}\left\{\left(\left(\boldsymbol{\varphi}_{i}^{V}\right)^{T} \mathbf{K}_{j 0} \boldsymbol{\varphi}_{i}^{V}+\left(\boldsymbol{\varphi}_{i}^{V}\right)^{T} \mathbf{K}_{0} \boldsymbol{\varphi}_{i}^{V}\right)\left(\boldsymbol{\varphi}_{i}^{V d}\right)^{T} \mathbf{K} \boldsymbol{\varphi}_{i}^{V d}\right\}} .
$$

Accordingly, the modified normalized indices are given as follows:

$$
\begin{gathered}
\operatorname{mmse}_{j}^{L}=\frac{\beta_{j}^{L}-\overline{\beta^{L}}}{\sigma_{\beta^{L}}}, \\
\operatorname{mmse}_{j}^{V}=\frac{\beta_{j}^{V}-\overline{\beta^{V}}}{\sigma_{\beta^{V}}},
\end{gathered}
$$

where $\varphi_{i}^{L}, \varphi_{i}^{V}$ are the lateral component and the vertical component of the $i$ th intact mode shape, respectively.

2.3. MCA-DI Method. As there are two damage indices, which may lead to confusion in the results when there is no previous information on whether the damage is in the beam or the column element, MCA-DI is therefore further developed to obtain more accurate and unambiguous results.

Wickramasinghe et al. [40] proposed a MF Change Percentage (MFC\%) method as follows: 


$$
\delta \%=\frac{\left[\sum_{i=1}^{n}\left(1 / \omega_{i}^{2}\right) \boldsymbol{\varphi}_{i}\left(\boldsymbol{\varphi}_{i}\right)^{T}\right]_{d}-\left[\sum_{i=1}^{n}\left(1 / \omega_{i}^{2}\right) \boldsymbol{\varphi}_{i}\left(\boldsymbol{\varphi}_{i}\right)^{T}\right]_{h}}{\left[\sum_{i=1}^{n}\left(1 / \omega_{i}^{2}\right) \boldsymbol{\varphi}_{i}\left(\boldsymbol{\varphi}_{i}\right)^{T}\right]_{h}},
$$

where $\delta \%$ is the indicator of MFC\% method, where $i, n$ are the mode number and total number of modes, respectively, $h, d$ represent health and damage, $\omega_{i}$ is the $i$ th natural circular frequency.
As each node in the members of $3 \mathrm{D}$ buildings has 3 translational degrees of freedom (DOFs), the MF matrix $\mathbf{M F}(2 L+V)$ of $j$ measurement locations will then be $3 j \times 3 j$ array instead of $j \times j$ for the asymmetric buildings, in which $L$ and $V$ are the lateral and vertical components of the mode shapes, respectively. Hence, the $i$ th modified $M F C \%$ can be expressed as follows:

$$
\mathbf{M M F} \%_{i}=\left[\begin{array}{ccccccc}
\delta \%_{11} & \delta \%_{12} & \delta \%_{13} & \cdots & \delta \%_{1(3 j-2)} & \delta \%_{1(3 j-1)} & \delta \%_{1(3 j)} \\
\delta \%_{21} & \delta \%_{22} & \delta \%_{23} & \cdots & \delta \%_{2(3 j-2)} & \delta \%_{2(3 j-1)} & \delta \%_{2(3 j)} \\
\delta \%_{31} & \delta \%_{32} & \delta \%_{33} & \cdots & \delta \%_{3(3 j-2)} & \delta \%_{3(3 j-1)} & \delta \%_{3(3 j)} \\
\vdots & \vdots & \vdots & \ddots & \vdots & \vdots & \vdots \\
\delta \%_{(k-2) 1} & \delta \%_{(k-2) 2} & \delta \%_{(k-2) 3} & \cdots & \delta \%_{(k-2)(3 j-2)} & \delta \%_{(k-2)(3 j-1)} & \delta \%_{(k-2)(3 j)} \\
\delta \%_{(k-1) 1} & \delta \%_{(k-1) 2} & \delta \%_{(k-1) 3} & \cdots & \delta \%_{(k-1)(3 j-2)} & \delta \%_{(k-1)(3 j-1)} & \delta \%_{(k-1)(3 j)} \\
\delta \%_{k 1} & \delta \%_{k 2} & \delta \%_{k 3} & \cdots & \delta \%_{k(3 j-2)} & \delta \%_{k(3 j-1)} & \delta \%_{k(3 j)}
\end{array}\right]_{3 j \times 3 j}
$$

The maximum absolute value in the $j$ th column of the above matrix can be written as follows:

$$
\max _{j}\left|\delta \%_{k(3 j)}\right|=\left[\max \left|\delta \%_{k 1}\right| \max \left|\delta \%_{k 2}\right| \max \left|\delta \%_{k 3}\right| \cdots \max \left|\delta \%_{k(3 j-2)}\right| \max \left|\delta \%_{k(3 j-1)}\right| \max \left|\delta \%_{k(3 j)}\right|\right]_{1 \times 3 j} .
$$

Considering the 3 DOFs of the member nodes, the maximum absolute values are extracted from every three $\delta \%{ }_{j}$ in the row

$$
\begin{aligned}
& \operatorname{mmf} \%(2 L+V)_{j} \\
& \quad=\max \left(\max _{(3 j-2)}\left|\delta \%_{k(3 j-2)}\right|: \max _{(3 j)}\left|\delta \%_{k(3 j)}\right|\right) .
\end{aligned}
$$

As there are three indicators $\delta \%_{j}, z_{j}^{L}$ and $z_{j}^{V}$, which may lead to confusion in the results, the new damage index $m$ is then developed by considering the results of the pair $\delta \%_{j}$ and $z_{j}^{L}$ and results of the pair $\delta \%_{j}$ and $z_{j}^{V}$ to calculate the most accurate results. In order to filter the interference term, it is necessary to extract the values larger than the average value.

$$
\begin{aligned}
\delta \%_{j} & = \begin{cases}\mathrm{mmf} \%(2 L+V)_{j}, & \mathrm{mmf} \%(2 L+V)_{j} \geq \overline{\mathrm{mmf} \%(2 L+V)_{j}}, \\
0, & \mathrm{mmf} \%(2 L+V)_{j}<\overline{\mathrm{mmf} \%(2 L+V)_{j}},\end{cases} \\
z_{j}^{L} & = \begin{cases}\mathrm{mmse}_{j}^{L}, & \mathrm{mmse}_{j}^{L} \geq \overline{\mathrm{mmse}^{L}}, \\
0, & \mathrm{mmse}_{j}^{L}<\overline{\mathrm{mmse}^{L}},\end{cases} \\
z_{j}^{V} & = \begin{cases}\mathrm{mmse}_{j}^{V}, & \mathrm{mmse}_{j}^{V} \geq \overline{\mathrm{mmse}^{V}}, \\
0, & \mathrm{mmse}_{j}^{V}<\overline{\mathrm{mmse}^{V}} .\end{cases}
\end{aligned}
$$


Results of the pair $\delta \%_{j}$ and $z_{j}^{L}$ and results of the pair $\delta \%_{j}$ and $z_{j}^{V}$ are given as follows:

$$
\begin{aligned}
& d^{L}= \begin{cases}\max \left(\delta \%_{j}, z_{j}^{L}\right), & \delta \%_{j}>0, z_{j}^{L}>0, \\
0, & \delta \%_{j} \leq 0 \text { or } / \text { and } z_{j}^{L} \leq 0,\end{cases} \\
& d^{V}= \begin{cases}\max \left(\delta \%_{j}, z_{j}^{V}\right), & \delta \%_{j}>0, z_{j}^{V}>0, \\
0, & \delta \%_{j} \leq 0 \text { or } / \text { and } z_{j}^{V} \leq 0 .\end{cases}
\end{aligned}
$$

Then the improved MCA-DI can be expressed as follows:

$$
m= \begin{cases}d^{L}, & \mathrm{DI}^{L}>0, \\ d^{V}, & \mathrm{DI}^{V}>0, \\ \max \left(\mathrm{DI}^{L}, \mathrm{DI}^{V}\right), & \mathrm{DI}^{L}>0, \mathrm{DI}^{V}>0 .\end{cases}
$$

\section{Application}

Before applying the developed technique to full-scale models, the proposed method was experimentally validated based on a laboratory model of an asymmetric building with mass eccentricity as presented in Wang et al. [35]. To eliminate the effects of changing environmental conditions, the modal test was conducted under similar environmental conditions. The validation of the modeling techniques was conducted by comparison of the experimental and numerical results for natural frequencies, mode shapes, and MAC values for both the healthy and the damaged building models. The establishment of the feasibility of the chosen damage detection indices provides adequate confidence in the procedure used in this paper for damage detection in asymmetric buildings and ensures its application to realistic full-scale building models.

\subsection{Building Types}

3.1.1. L-Shape Building: Description and Vibration Characteristics. The model of 10-storey L-shape asymmetric building is generated in ANSYS [41]. The model of this structure is designed to be reinforced concrete with $40 \mathrm{~m}$ in height, $24 \mathrm{~m}$ in width, and $32 \mathrm{~m}$ in length. It consists of 140 columns $(1200 \mathrm{~mm} \times 500 \mathrm{~mm})$ of length $4000 \mathrm{~mm}$ and 190 beams $(600 \mathrm{~mm} \times 400 \mathrm{~mm})$ of length $8000 \mathrm{~mm}$. The general modeling scheme is shown in Figure 1. The material properties are consistent for all three asymmetric structures listed in Table 1. Assume the flexural rigidity EI to be constant and ignore the damping effect. Then the modal analysis is performed so that the natural frequencies and mode shapes of the structure are obtained. The first five modes of the healthy structure are obtained. As expected, all modes obtained from FE analyses included torsional components. The first bending mode vibration is dominant in the $x$-direction and coupled with torsion in the anticlockwise direction, while the second bending mode vibrates mainly in the vertical coupled with torsion in the clockwise direction, as shown in Figure 2. The third mode is the vibration of torsion, while the fourth and fifth modes are bending modes coupled with torsion.

3.1.2. Setback Building: Description and Vibration Characteristics. The 10-storey setback building structure is designed as shown in Figure 3. This reinforced concrete structure has a height of $40 \mathrm{~m}$, a width of $24 \mathrm{~m}$, and a length of $40 \mathrm{~m}$. All columns of the developed structure are $4000 \mathrm{~mm}$ in height in each storey with dimensions of $1200 \mathrm{~mm} \times 500 \mathrm{~mm}$, and all beams are $8000 \mathrm{~mm}$ in length with dimensions of $600 \mathrm{~mm} \times 400 \mathrm{~mm}$. The proposed structure is studied for its free vibration properties without damping effect. The first five modes are obtained from FE analysis. It is observed that only the first mode of this 10storey setback building model is similar to the L-shape building model. The other four modes are significantly different. The first mode of this setback building predominantly vibrates along with the $x$-axis of the cross-section coupled with torsional vibration in a clockwise direction, as shown in Figure 4 . There is an obvious difference of the second mode from that in the L-shaped model; it mainly vibrates in the direction between $x$ and $z$ axes. This means the second weaker axis of this setback building model is in the direction between $x$ and $z$ axes, instead of being along the $z$-axis as in the L-shaped building model. The coupling of torsional mode is also not as obvious as in the L-shaped building, but it is still coupled and causes a rotation in the anticlockwise sense. As expected, the third mode is the first torsional mode and vibrates in the clockwise direction. The fourth mode is the second translational mode in $x$-direction coupled with anticlockwise torsion. The fifth mode is the second torsional mode but coupled with bending in the upper level of the structure. This is because the setback structure is weaker in the upper part compared to other prismatic structures.

\subsubsection{Building with Unsymmetrical Distribution of Columns:} Description and Vibration Characteristics. The 6-storey reinforced concrete building structure with the unsymmetrical distribution of columns is developed as shown in Figure 5. The FE model of this structure is designed to be reinforced concrete with $24 \mathrm{~m}$ in height, $20 \mathrm{~m}$ in width, and $42 \mathrm{~m}$ in length. All columns of the developed structure are $4 \mathrm{~m}$ in height in each floor with dimensions of $1200 \mathrm{~mm} \times 500 \mathrm{~mm}$ and the beams have varying lengths from $2000 \mathrm{~mm}$ to $12000 \mathrm{~mm}$ with a dimension of $600 \mathrm{~mm} \times 400 \mathrm{~mm}$. The proposed structure is also analyzed for its free vibration properties without damping effect, and the first five modes are obtained from FE analysis. It was observed that the first mode vibrates dominantly along the $x$ axis direction and that the coupling of the torsional mode is not very distinct, as shown in Figure 6. The second mode is supposed to be vibrating mainly in the $z$-axis direction, but in this particular building, it vibrates less along the $z$-axis and has a greater coupling with a torsional mode due to its special structural irregularity. The third mode is a torsional mode, while the fourth and fifth modes are bending modes coupled with torsion. It is hence evident that these mode 


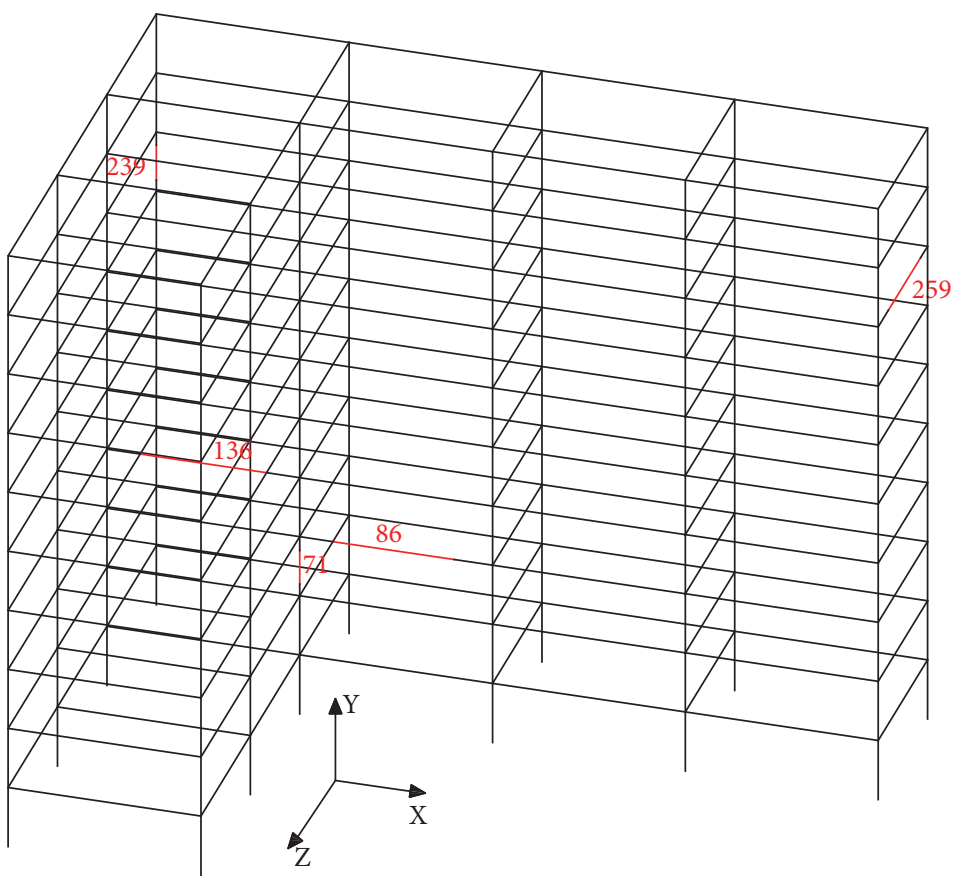

(a)

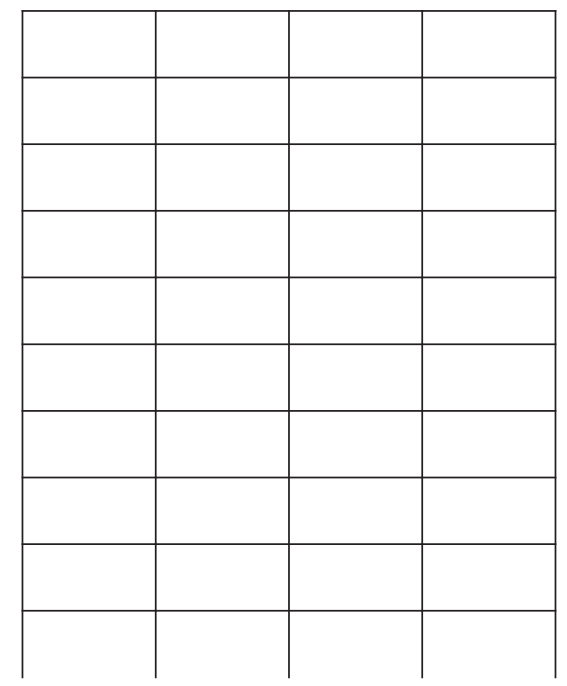

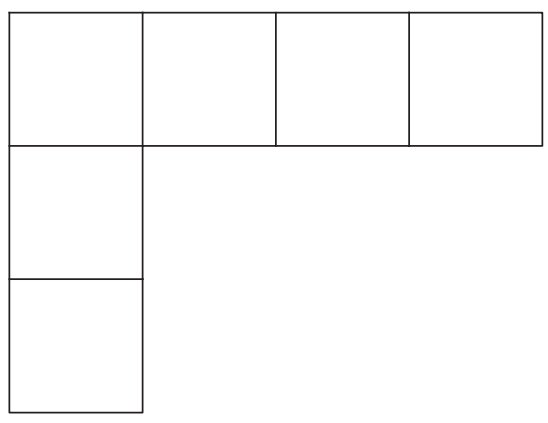

(b)

(c)

Figure 1: The general modeling scheme and induced damage members of L-shaped structure. (a) 3D view. (b) Plan view. (c) Elevation view.

TABLE 1: Geometric and material properties for FEM.

\begin{tabular}{lccccc}
\hline Member & Element type & Material & Poisson's ratio & Density $\left(\mathrm{kg} / \mathrm{m}^{3}\right)$ & Modulus of elasticity (GPa) \\
\hline Beam (all) & Beam 188 & RC & 0.3 & 2427 & 42 \\
Column (all) & Beam 188 & RC & 0.3 & 2427 & 42 \\
\hline
\end{tabular}

shapes are quite different from those in a symmetric building structure with a prismatic rectangular plan. The vibration characteristics in the three asymmetric buildings are not only complex but also different from each other. These differences cause complexities in applying the usual vibration-based damage detection methods and confirm the need for (i) the development of a method to treat damage detection in asymmetric buildings and (ii) investigate the feasibility of the method on different types of asymmetric buildings.

3.2. Damage Scenarios. In order to exhibit the good application of the method proposed above, three different types of asymmetrical buildings are considered in which five 


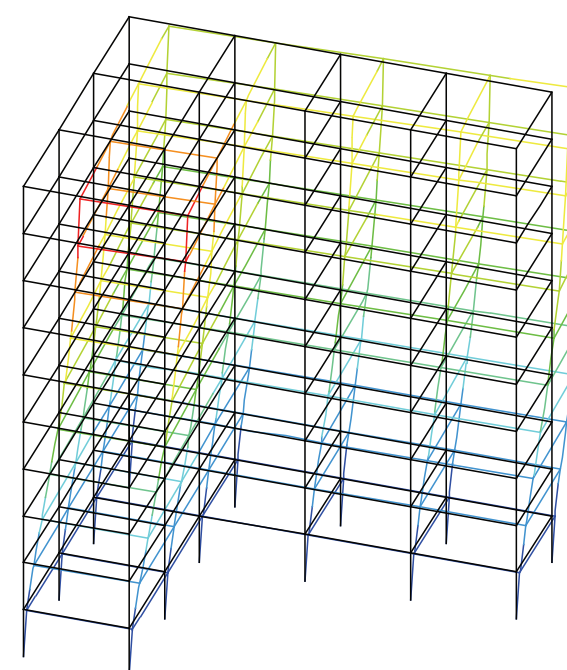

(a)

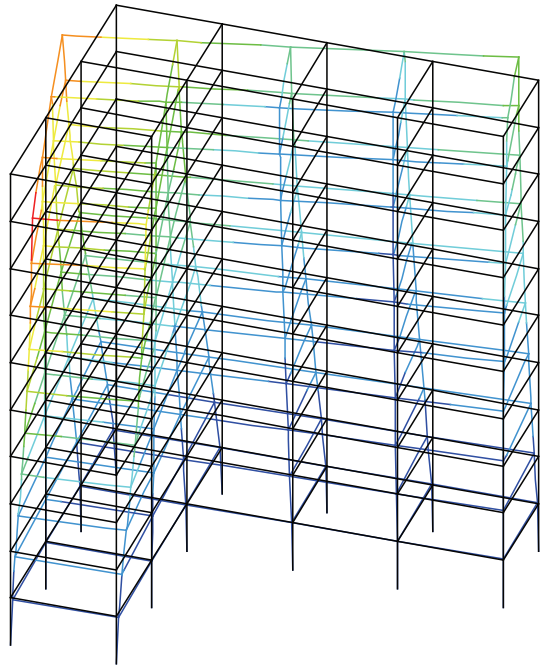

(c)

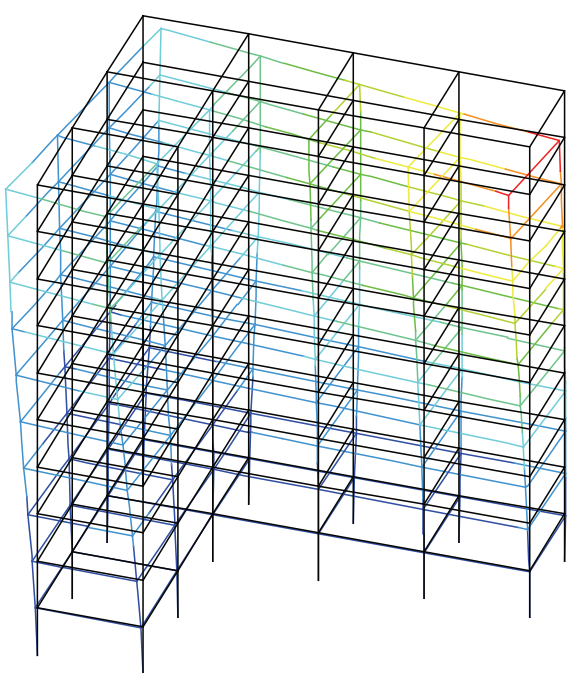

(b)

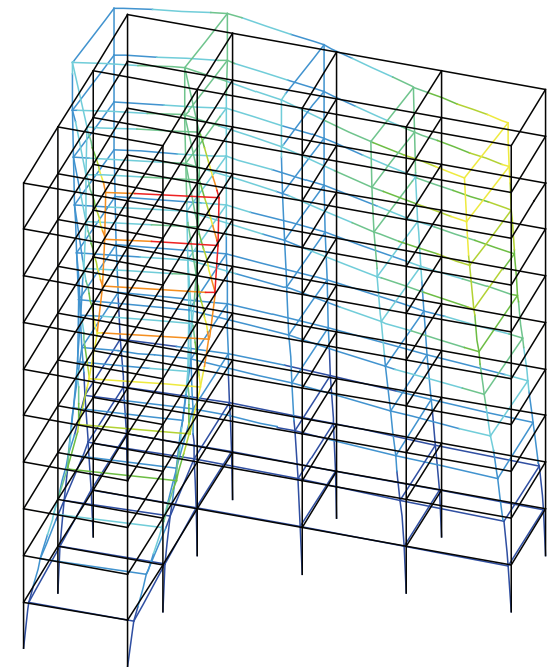

(d)

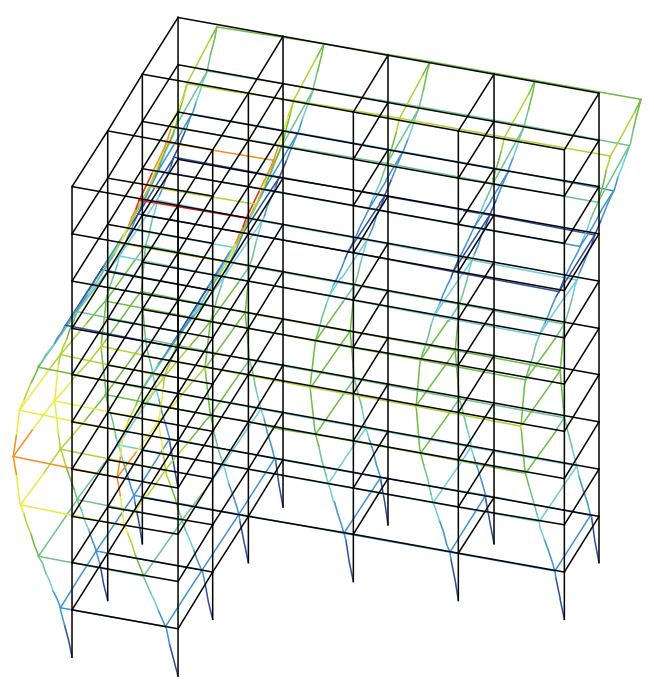

(e)

Figure 2: First 5 modes of L-shaped building model. (a) 1st mode $(0.69 \mathrm{~Hz})$. (b) 2nd mode $(0.79 \mathrm{~Hz})$. (c) $3 \mathrm{rd}$ mode $(0.87 \mathrm{~Hz})$. (d) 4 th mode $(1.78 \mathrm{~Hz})$. (e) 5 th mode $(2.22 \mathrm{~Hz})$. 


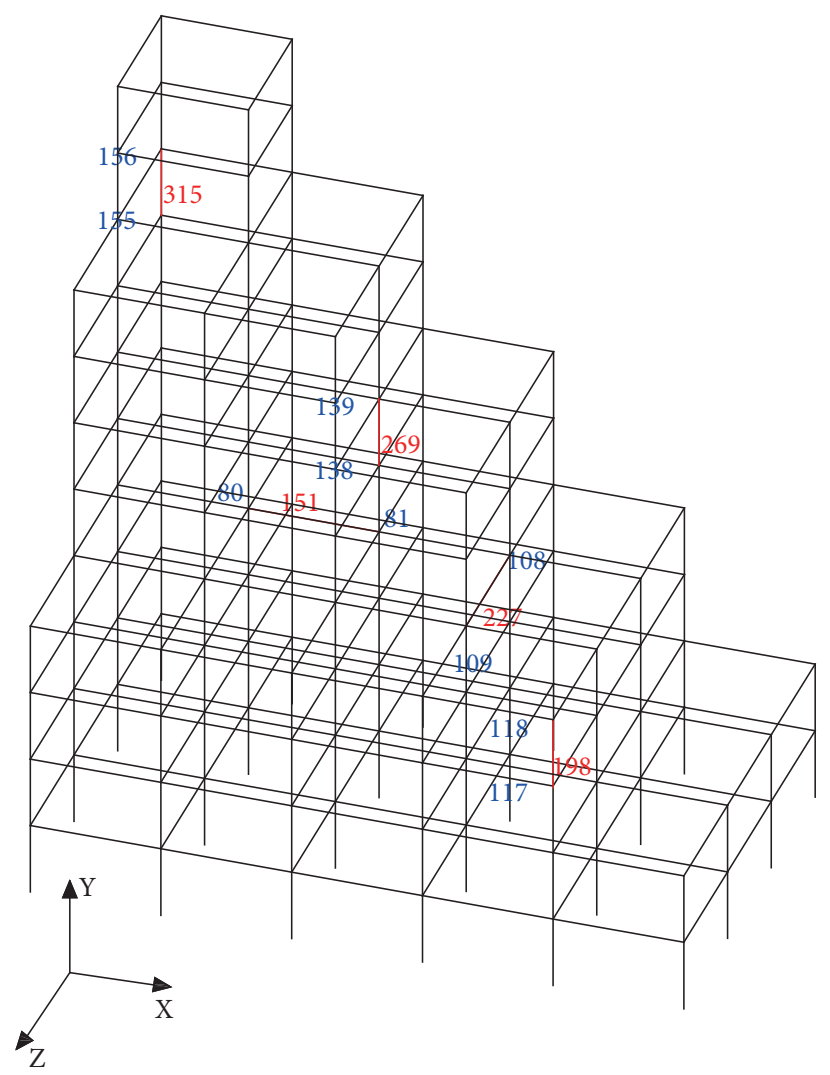

(a)

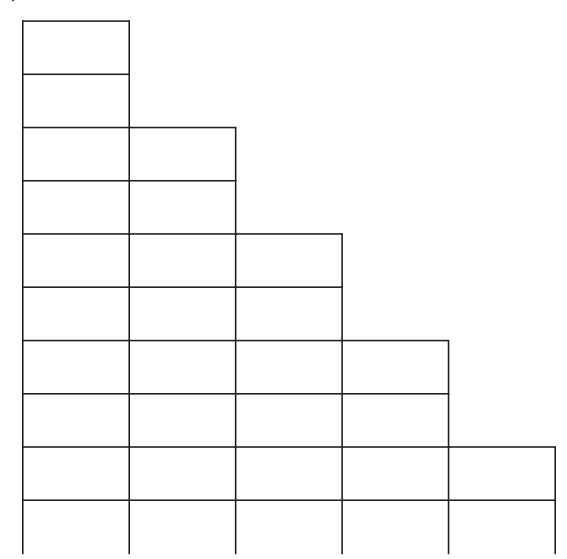

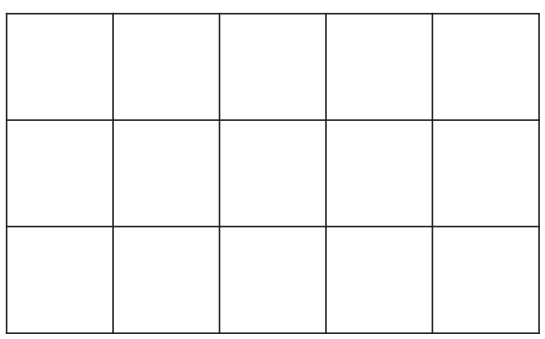

(b)

(c)

Figure 3: The general modeling scheme and induced damage members of the setback structure. (a) 3D view. (b) Plan view. (c) Elevation view.

different damage scenarios are applied, as shown in Tables 2-4. The first two damage cases are single damage cases with stiffness reductions across the full length of the column or the beam. In the different types of asymmetric building structures, mild and severe damage cases are represented by different extents of damage (5\% to 30\%). The other three cases are designed to have multiple-damage locations so as to seek the degree of interaction between a damaged member and the elements in its vicinity. The damaged members are highlighted in Figures 1, 3, and 5.

\subsection{Results and Discussion}

3.3.1. L-Shape Building. Figures 7 and 8 show the DI results of single damage cases. It can be seen that the damaged elements are clearly identified by the two distinct peaks. Results of multiple-damage cases are presented in Figures 9-11. Again, the results correctly located all damages. From the results of damage scenario D4 in Figure 10, it demonstrates that the damaged member itself inevitably gets a large DI value so are the members connected to it. The 


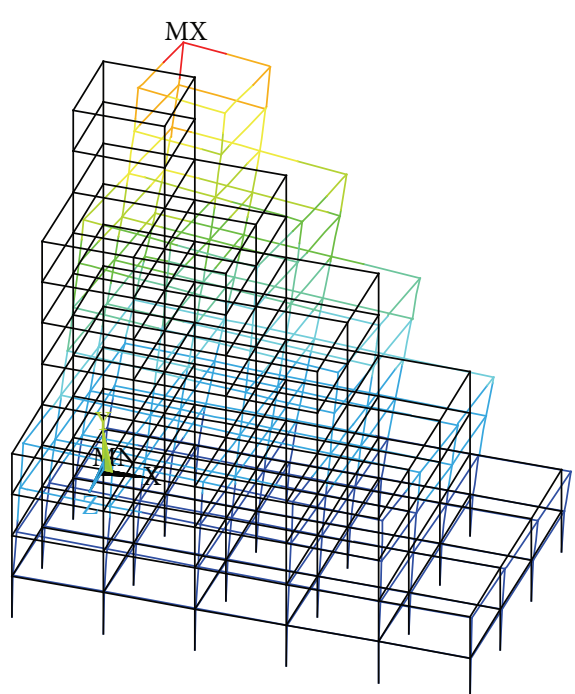

(a)

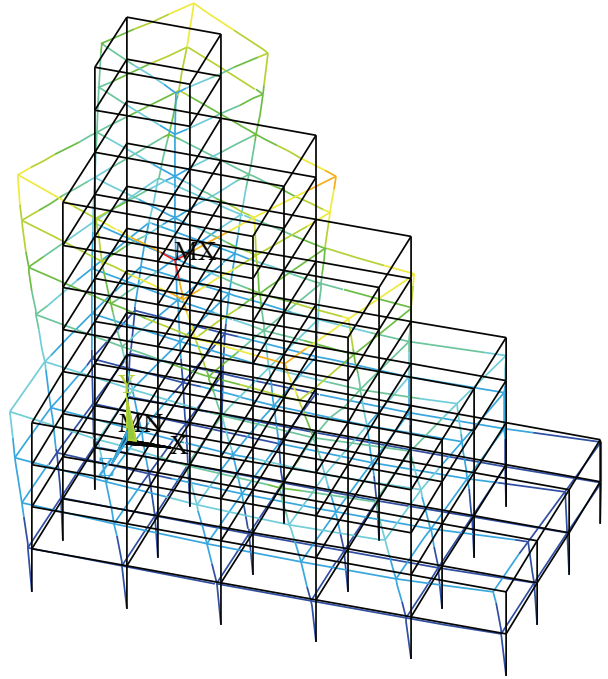

(c)

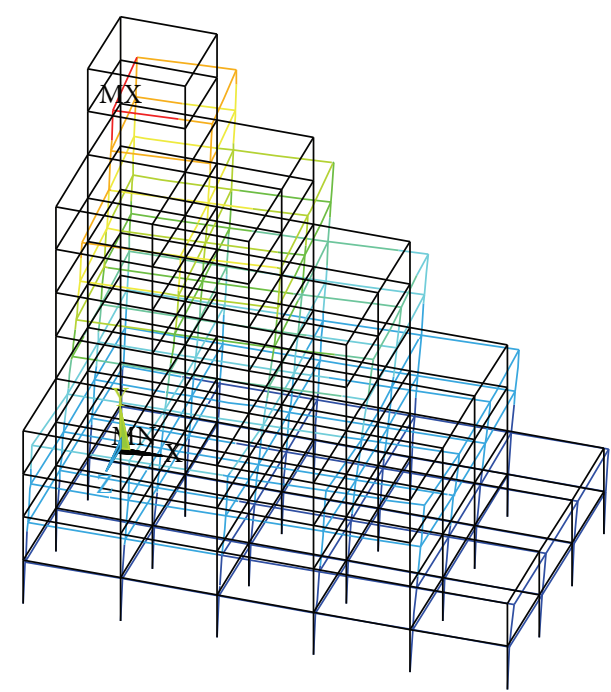

(b)

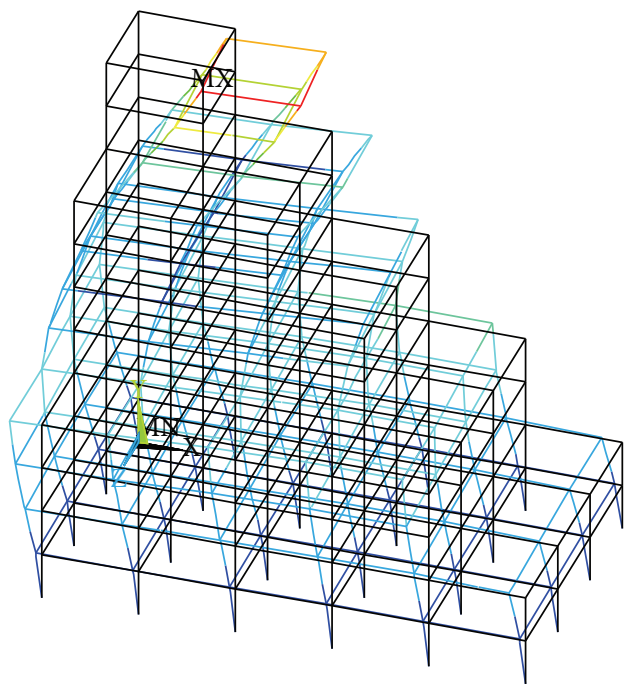

(d)

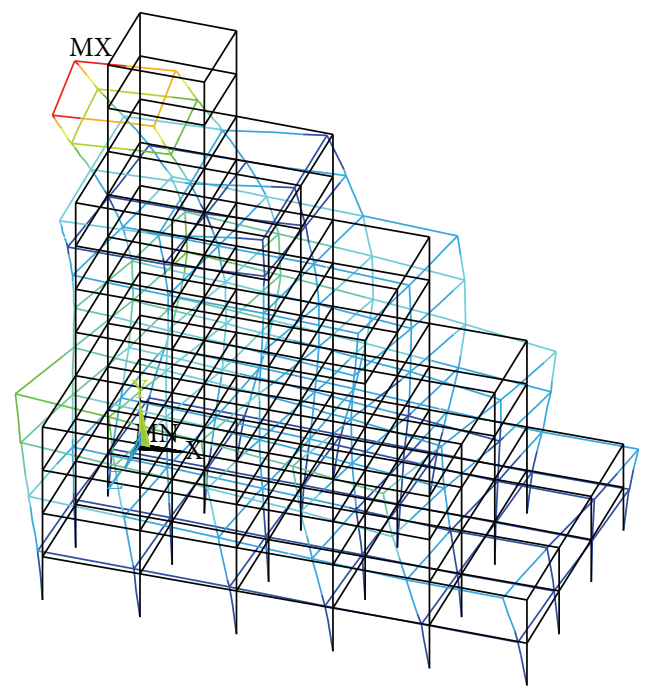

(e)

Figure 4: First 5 modes of setback building model. (a) 1st mode $(1.0 \mathrm{~Hz})$. (b) 2nd mode $(1.08 \mathrm{~Hz})$. (c) $3 \mathrm{rd} \mathrm{mode} \mathrm{(1.65} \mathrm{Hz).} \mathrm{(d)} 4$ th mode $(2.41 \mathrm{~Hz})$. (e) 5 th mode $(2.86 \mathrm{~Hz})$ 


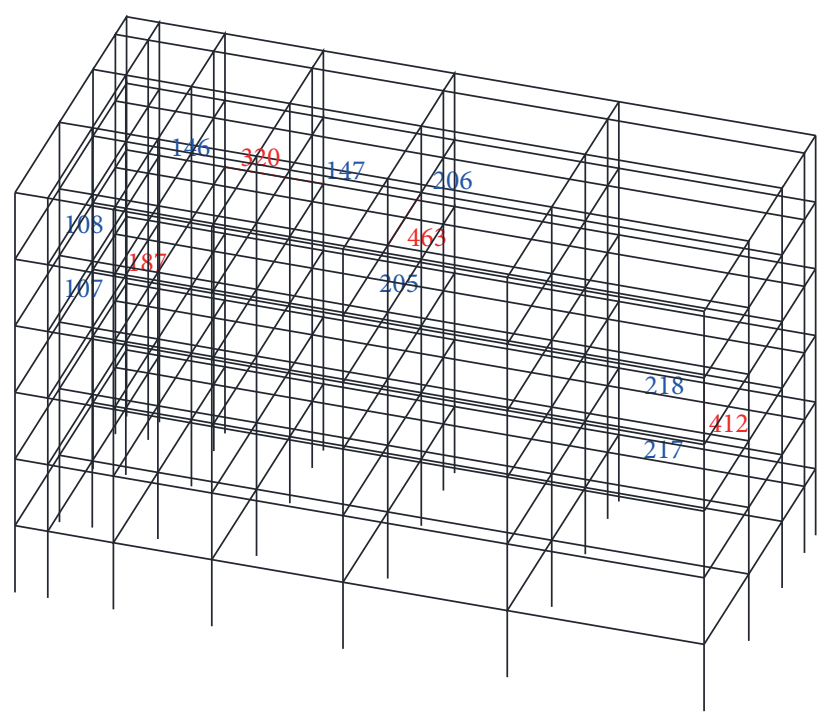

(a)

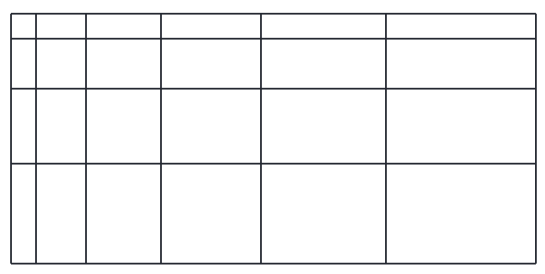

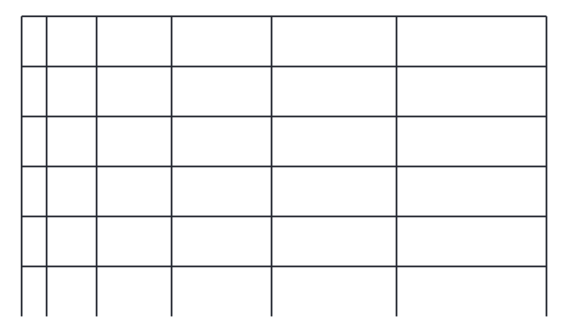

(b)

(c)

Figure 5: The general modeling scheme and induced damage members of building with the unsymmetrical distribution of columns. (a) 3D view. (b) Plan view. (c) Elevation view.

results also provide evidence that the estimation of damage severity in column elements is more difficult than in beam elements by using the proposed MCA-DI. However, the results can indicate the relative severity between those damages.

(1) Results with Measurement Noise. Measurement noise is unavoidable in practice and its effect on damage detection needs to be considered. It is then necessary to examine the performance of the proposed method in the presence of measurement noise. Messina et al. [42] suggested a standard error of $\pm 0.15 \%$ as a benchmark figure for modal frequencies measured in the laboratory with the impulse hammer technique. In contrast, the mode shape estimate has an error level as much as 20 times worse than those in the corresponding modal frequency estimate [43]. Therefore, the noise level for the mode shape is initially assumed to be $3 \%$. For further investigating the noise effect on the proposed method, a higher noise level (5\%) on the mode shape is used. Moreover, as the frequency error is quite low, only the mode shapes which are generated from FE analysis are contaminated with noise. Mode shape in the presence of noise can be simulated as follows [44]:

$$
\overline{\boldsymbol{\varphi}_{i j}}=\boldsymbol{\varphi}_{i j}\left(1+\gamma_{i j}^{\varphi} \rho^{\varphi}\right)\left|\boldsymbol{\varphi}_{\max , i}\right|,
$$

where $\overline{\varphi_{i j}}$ and $\varphi_{i j}$ are the $j$ th components of $i$ th mode shape with and without noise, respectively; $\gamma_{i j}^{\varphi}$ is a random number with the mean equal to 0 and the variance of $1 ; \rho^{\varphi}$ is the random noise level considered; $\varphi_{\max , i}$ is the largest component in the $i$ th mode shape.

The noisy mode shapes are then used to localize the structural damage. Figures 12 and 13 below give the results for the two single damage scenarios. As the original plots are congested to clearly show the location of damage, the enlarged plots are shown in the figures below the original plots to clearly identify the damage location (the enlarged area is highlighted with the red boxes in the upper Figures). For both cases, the results show similar features for noise-free data and under both $3 \%$ and 5\% noisy modal data.

Figures 14-16 give the damage localization results for the three multiple-damage scenarios. The results indicate that the noise has no effect on the results when using proposed MCA-DI in one beam and one column damage case and multibeam case. While in the multicolumn damage case under 5\% noise level, there is another indication in addition to damaged element. It is noticed that the indicated element is a column element connected to the damaged column element in the upper level. The elements connected to the damaged element exhibit some damage characteristics in the modal data of the shared nodes. It is hence reasonable to have a large value of the DI in these elements as well. 


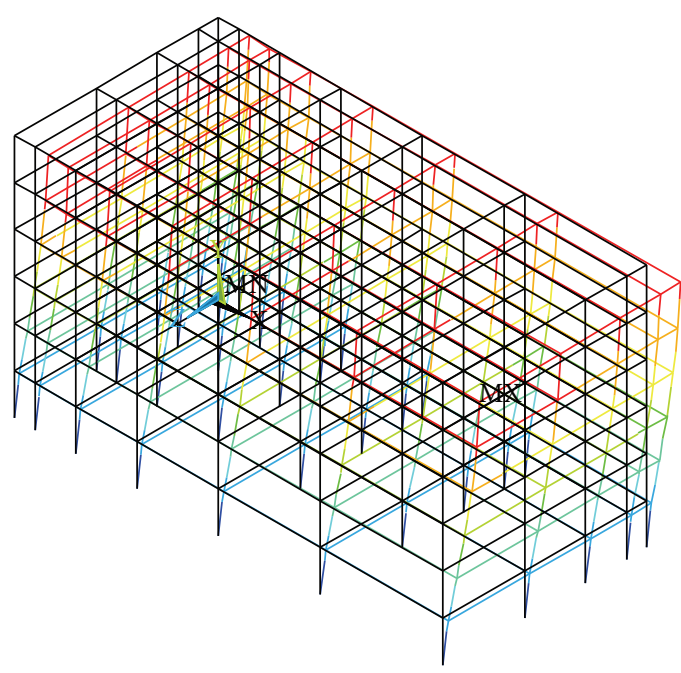

(a)

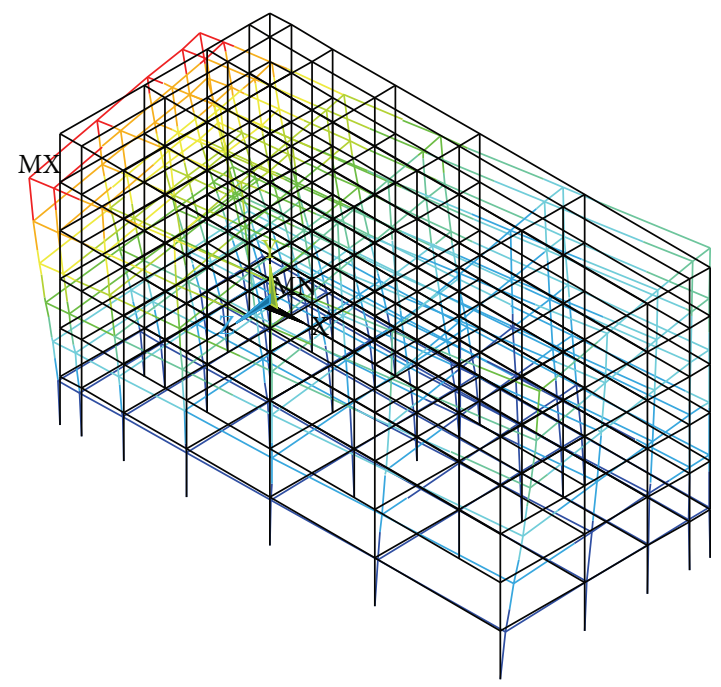

(c)

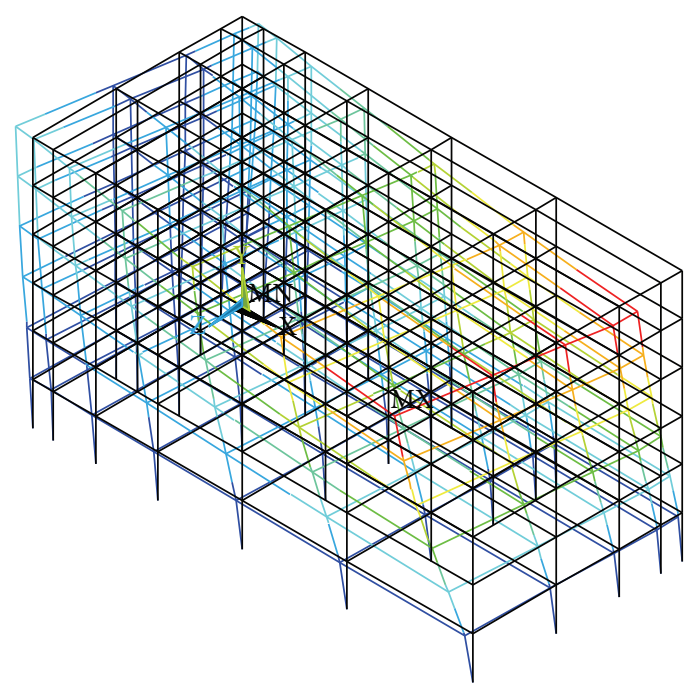

(b)

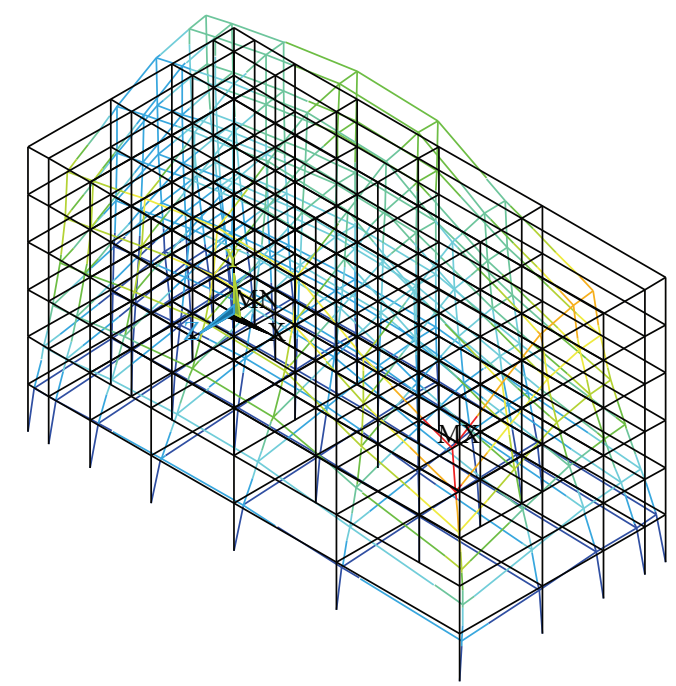

(d)

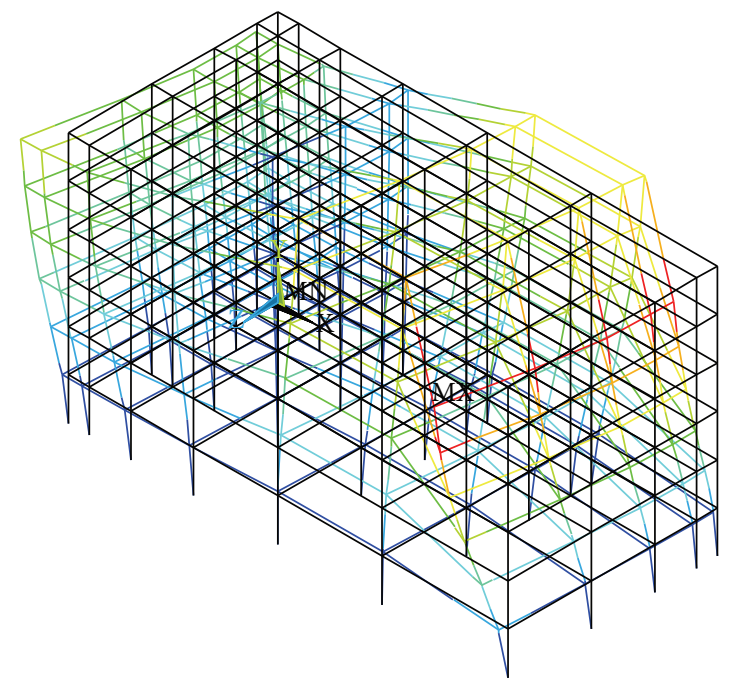

(e)

FIGURE 6: First 5 modes of building with the unsymmetrical distribution of columns model. (a) 1st mode (1.41 Hz). (b) $2 \mathrm{nd} \mathrm{mode} \mathrm{(1.83} \mathrm{Hz).}$ (c) 3rd mode $(2.07 \mathrm{~Hz})$. (d) 4 th mode $(3.17 \mathrm{~Hz})$. (e) 5 th mode $(3.81 \mathrm{~Hz})$. 
TABLE 2: Damage scenarios of 10-storey L-shape building.

\begin{tabular}{lccccc}
\hline Scenarios & D1 & D2 & D3 & D4 & D5 \\
\hline Damaged element no. & 71 (column) & 86 (beam) & 136 (beam) and 239 (column) & 86 (beam) and 259 (beam) & $\begin{array}{c}71 \text { (column) and 239 } \\
\text { (column) }\end{array}$ \\
Stiffness reduction rate (\%) & 30 & 30 & 30 and 30 & 30 and 10 & 10 and 30 \\
\hline
\end{tabular}

TABLE 3: Damage scenarios of 10-storey setback building.

\begin{tabular}{lccccc}
\hline Scenarios & D1 & D2 & D3 & D4 & D5 \\
\hline $\begin{array}{l}\text { Damaged element no. } \\
\begin{array}{l}\text { Stiffness reduction rate } \\
(\%)\end{array}\end{array}$ & $\begin{array}{c}269 \\
\text { column})\end{array}$ & $\begin{array}{c}151 \\
\text { (beam) }\end{array}$ & $\begin{array}{c}227 \text { (beam) and 315 } \\
\text { (column) }\end{array}$ & $\begin{array}{c}\text { 151 (beam) and 227 } \\
\text { (beam) }\end{array}$ & $\begin{array}{c}151 \text { (beam), 227 (beam), and 315 } \\
\text { (column) }\end{array}$ \\
\hline
\end{tabular}

TABLE 4: Damage scenarios of a 6-storey building with unsymmetrical distribution of columns.

\begin{tabular}{|c|c|c|c|c|c|}
\hline Scenarios & $\mathrm{D} 1$ & $\mathrm{D} 2$ & D3 & $\mathrm{D} 4$ & D5 \\
\hline Damaged element no. & $\begin{array}{c}187 \\
\text { (column) }\end{array}$ & $\begin{array}{c}320 \\
\text { (beam) }\end{array}$ & $\begin{array}{l}463 \text { (beam) and } 412 \\
\text { (column) }\end{array}$ & $\begin{array}{l}320 \text { (beam) and } 463 \\
\text { (beam) }\end{array}$ & $\begin{array}{c}320 \text { (beam), } 463 \text { (beam), and } 412 \\
\text { (column) }\end{array}$ \\
\hline $\begin{array}{l}\text { Stiffness reduction rate } \\
(\%)\end{array}$ & 10 & 5 & 10 and 10 & 10 and 20 & 10,20 , and 30 \\
\hline
\end{tabular}

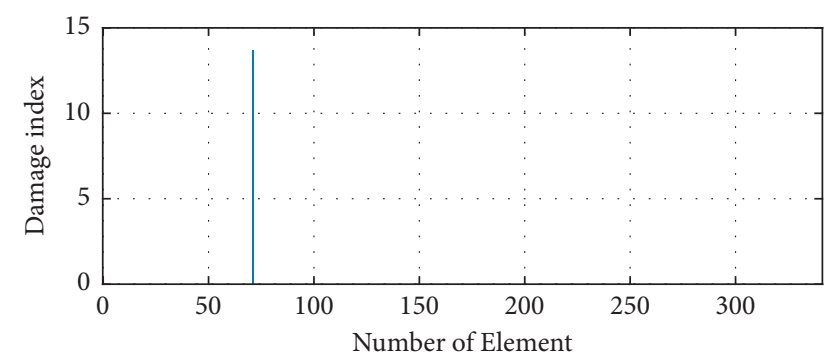

FIGURE 7: Results of D1 using MCA-DI (L-shape building).

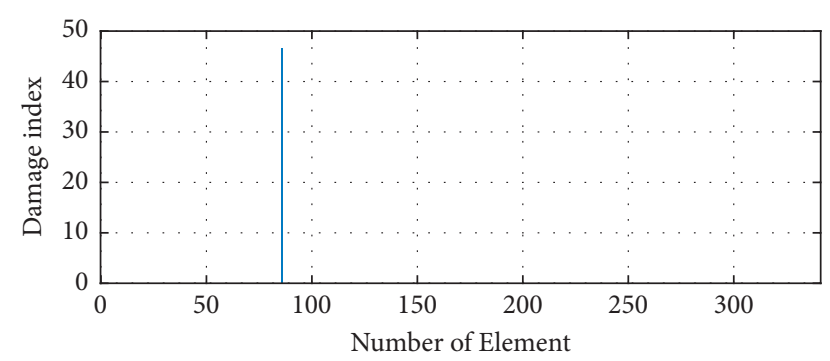

Figure 8: Results of D2 using MCA-DI (L-shape building).

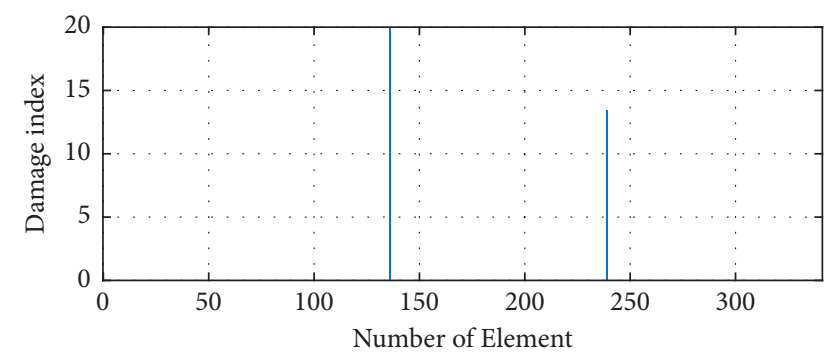

Figure 9: Results of D3 using MCA-DI (L-shape building).

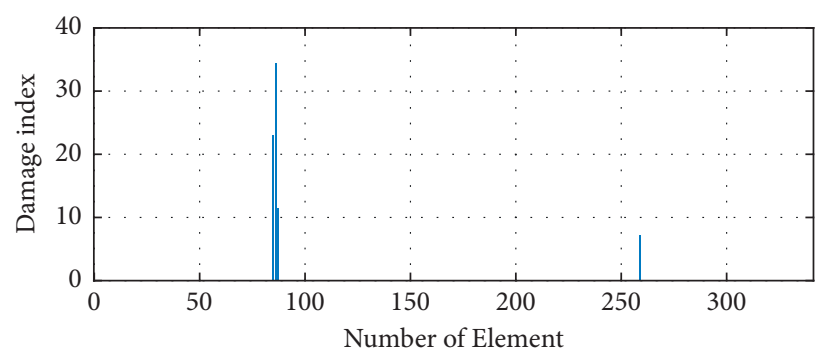

FIgURE 10: Results of D4 using MCA-DI (L-shape building).

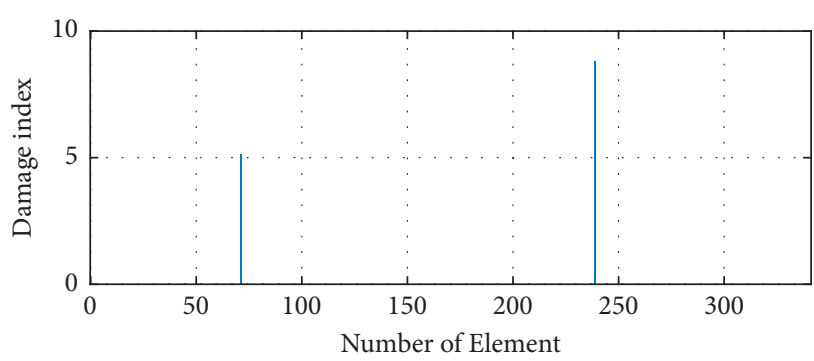

FIgure 11: Results of D5 using MCA-DI (L-shape building).

For further investigating the noise effect on the proposed method, the effect of a higher level of $10 \%$ random noise for mode shapes is investigated. Previous results show that the noise has more effect on the results when damage is in column elements. So, the effect of larger noise is studied only with the damage in single and multicolumn damage cases (damage cases D1 and D5).

The damage detection results from the MCA-DI method using the first 5 modes in the calculation for damage cases D1 and D5 are shown in Figures 17 and 18, respectively. For 


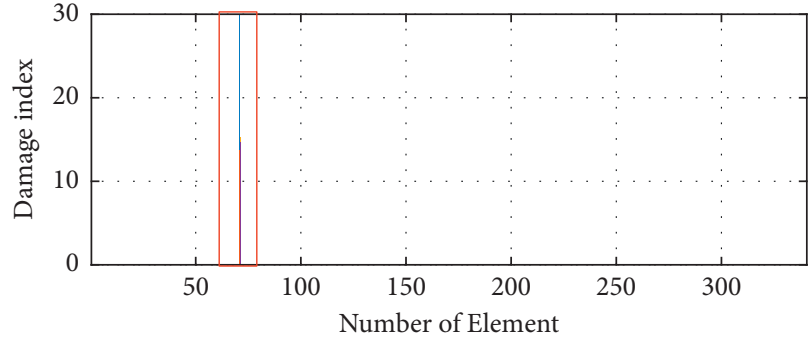

True Damage
DI
DI with $3 \%$ noise

DI with $5 \%$ noise

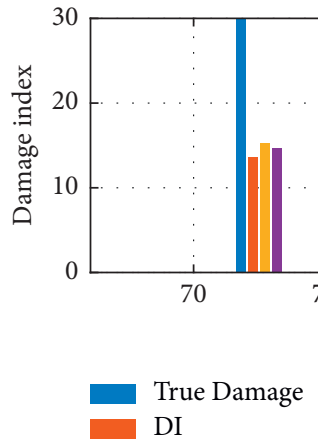

DI

(a)

FIGURE 12: Results of single-damage scenario D1 containing measurement noise. (a) Original result. (b) Zoomed result.

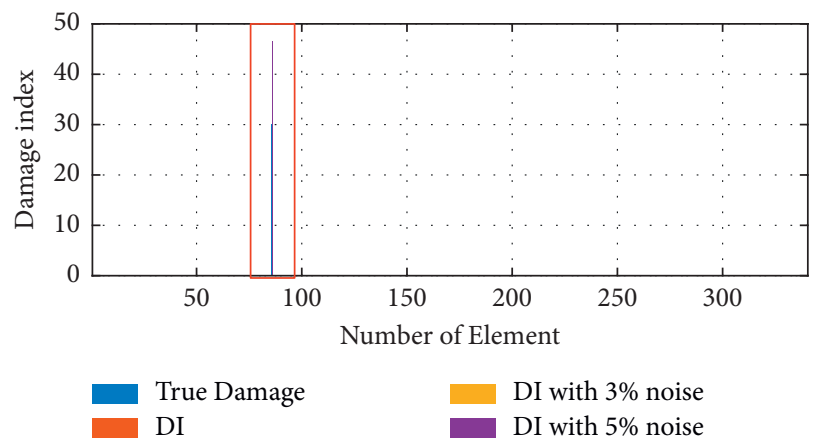

(a)

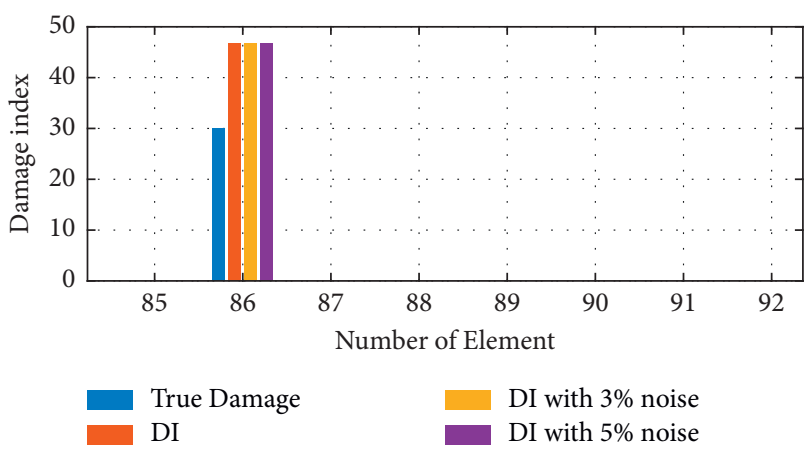

(b)

FIGURE 13: Results of single-damage scenario D2 containing measurement noise. (a) Original result. (b) Zoomed result.

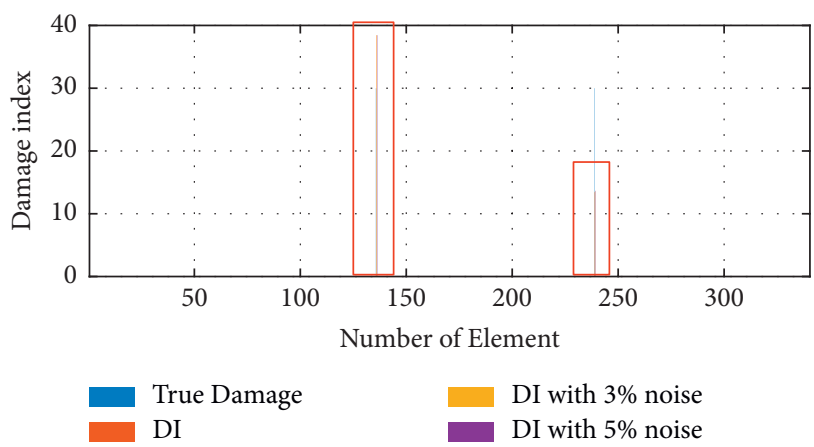

(a)

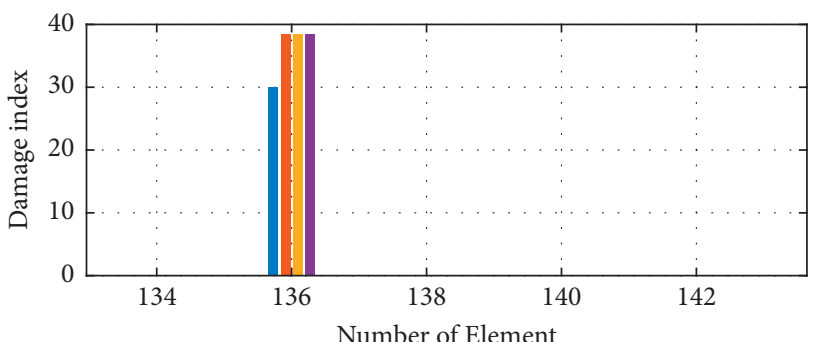

True Damage DI
I with $3 \%$ noise DI with $5 \%$ noise

(b)

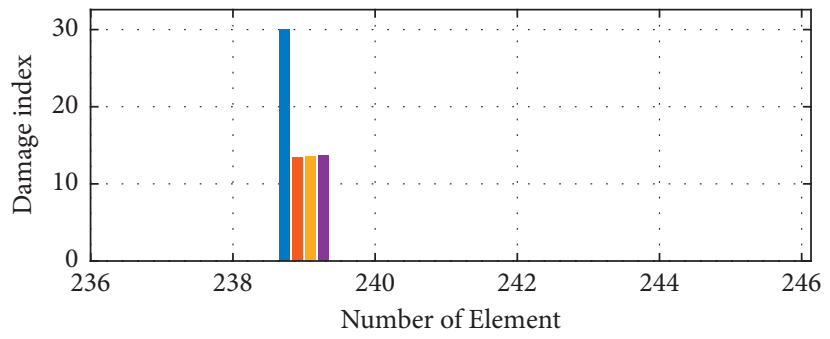

True Damage $\quad$ DI with $3 \%$ noise

(c)

Figure 14: Results of multiple-damage scenario D3 containing measurement noise. (a) Original result. (b) Zoomed result part 1. (c) Zoomed result part 2 . 


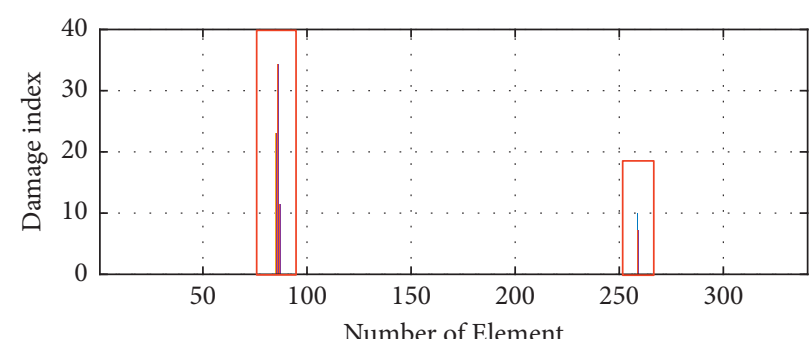

True Damage
DI
$\begin{array}{ll}\text { DI with } 3 \% \text { noise } \\ \text { DI with } 5 \% \text { noise }\end{array}$

(a)

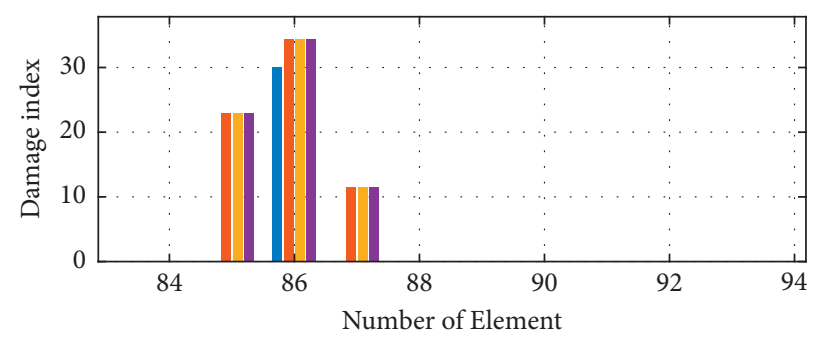

True Damage DI
DI with $3 \%$ noise DI with $5 \%$ noise

(b)

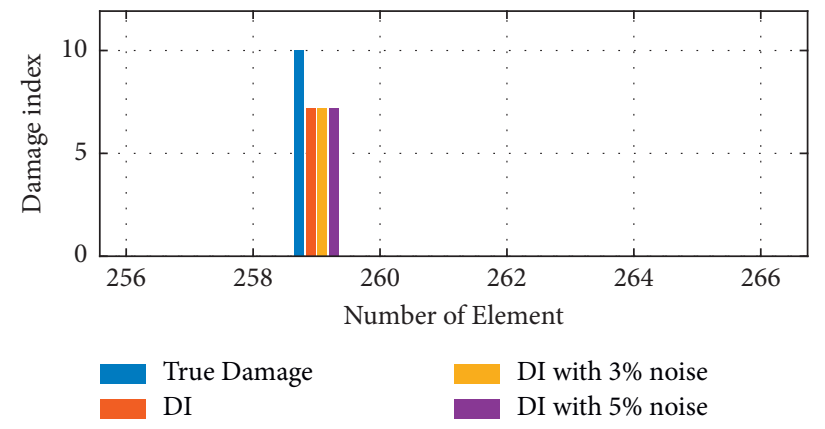

(c)

FIGURE 15: Results of multiple-damage scenario D4 containing measurement noise. (a) Original result. (b) Zoomed result part 1. (c) Zoomed result part 2 .

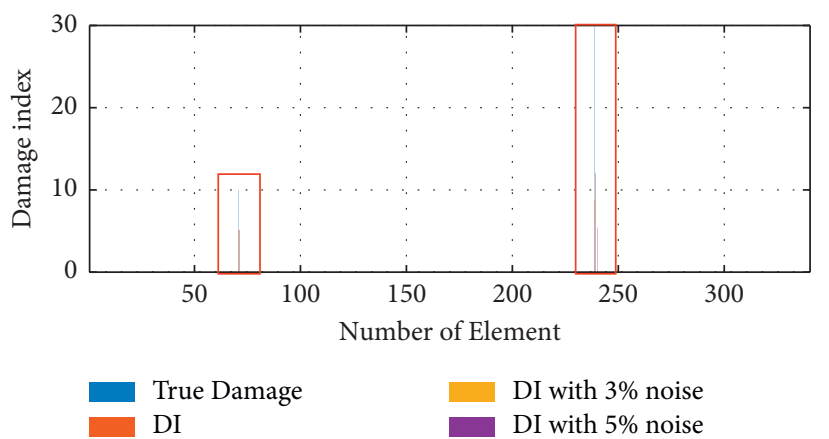

(a)

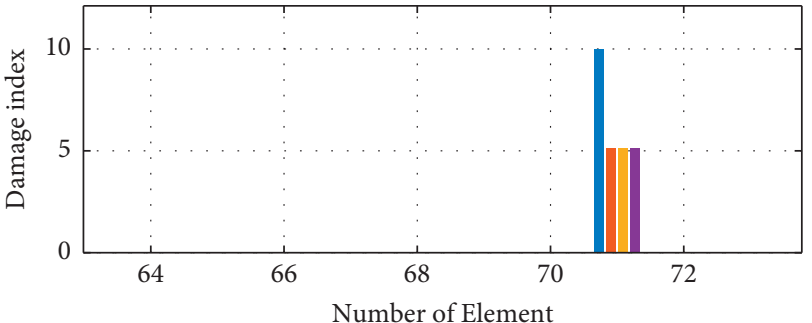

True Damage DI
DI with $3 \%$ noise

DI with $5 \%$ noise

(b)

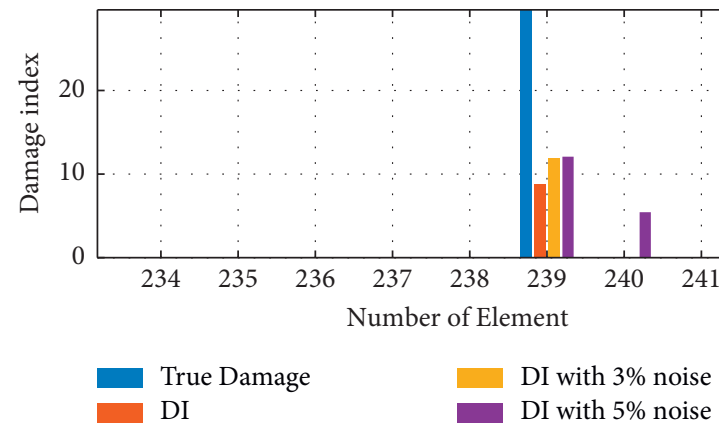

(c)

FiguRE 16: Results of multiple-damage scenario D5 containing measurement noise. (a) Original result. (b) Zoomed result part 1. (c) Zoomed result part 2. 


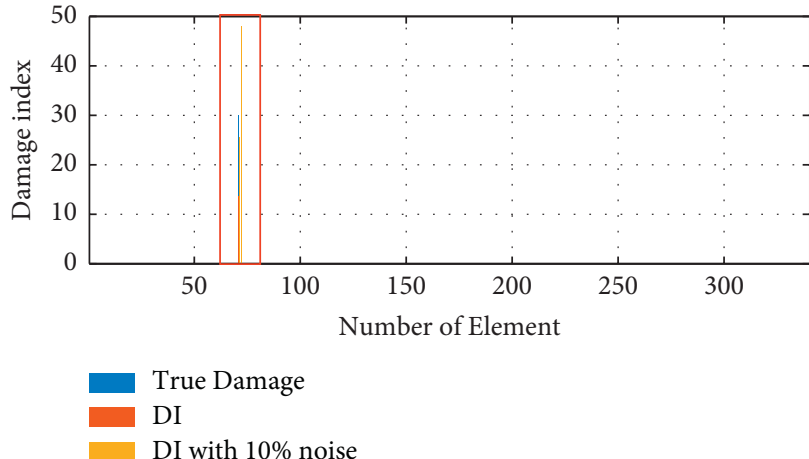

(a)

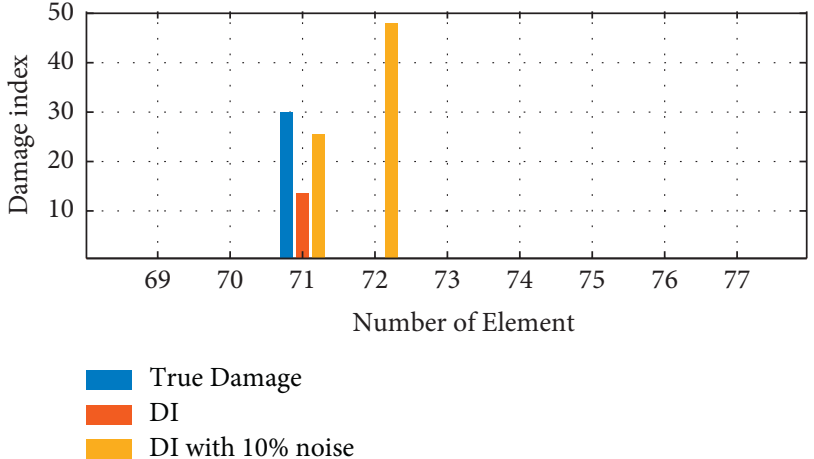

(b)

Figure 17: Results of single-damage scenario D1 containing 10\% measurement noise. (a) Original result. (b) Zoomed result.

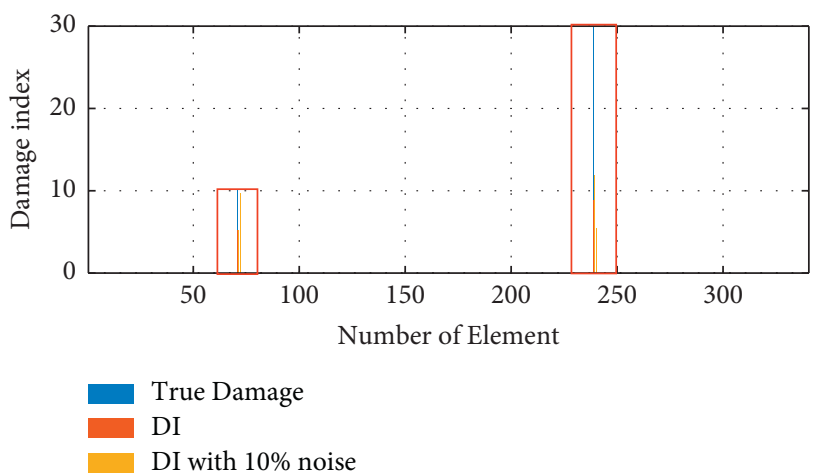

(a)

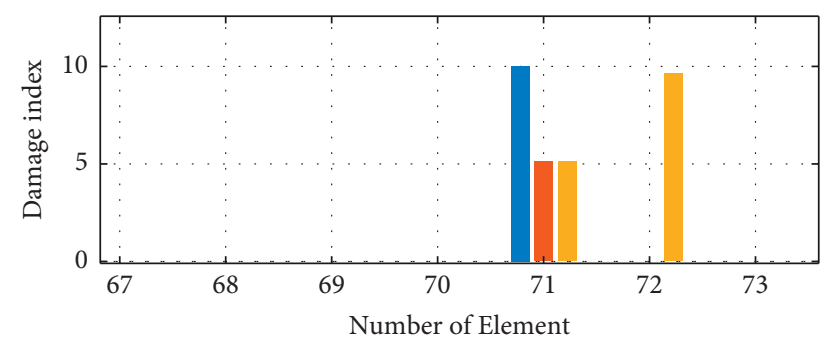

True Damage

DI

DI with $10 \%$ noise

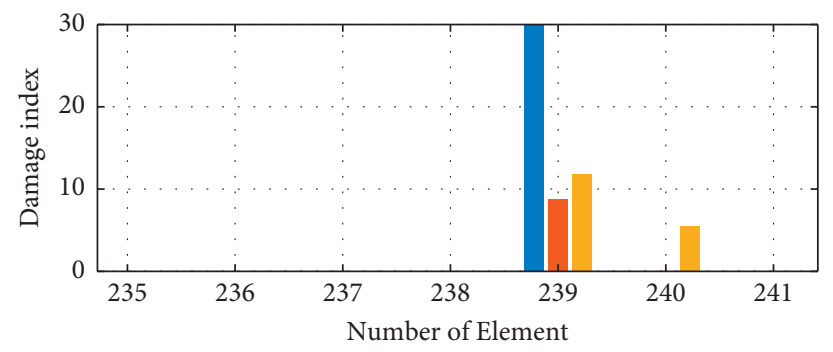

True Damage

DI

DI with $10 \%$ noise

(c)

Figure 18: Results of multiple-damage scenario D5 containing 10\% measurement noise. (a) Original result. (b) Zoomed result part 1. (c) Zoomed result part 2.

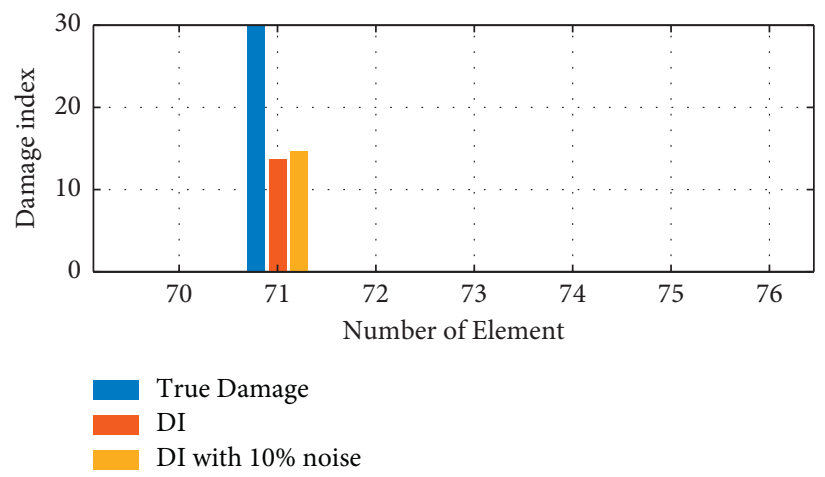

Figure 19: Results of damage scenario D1 containing 10\% measurement noise using first 3 modes enlarged result. 


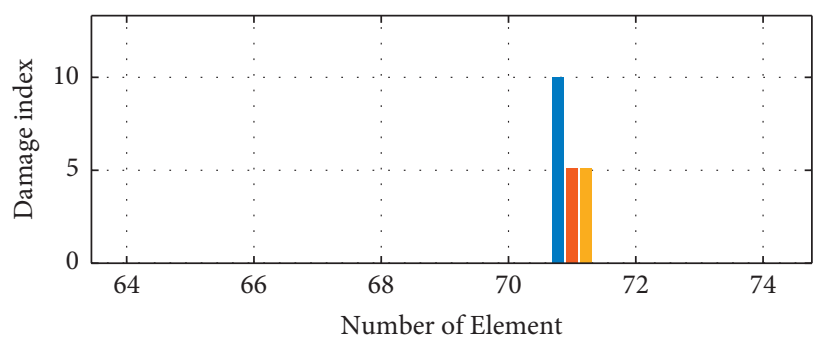

True Damage

DI

DI with $10 \%$ noise

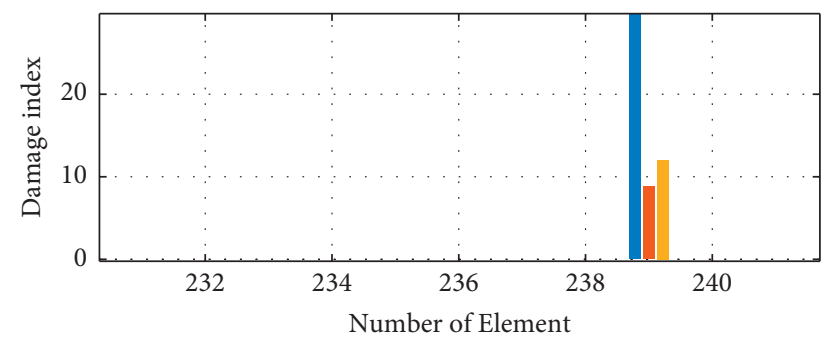

True Damage

DI

DI with $10 \%$ noise

(a)

(b)

Figure 20: Results of damage scenario D5 containing 10\% measurement noise using only first 3 modes. (a) Zoomed result part 1 . (b) Zoomed result part 2.

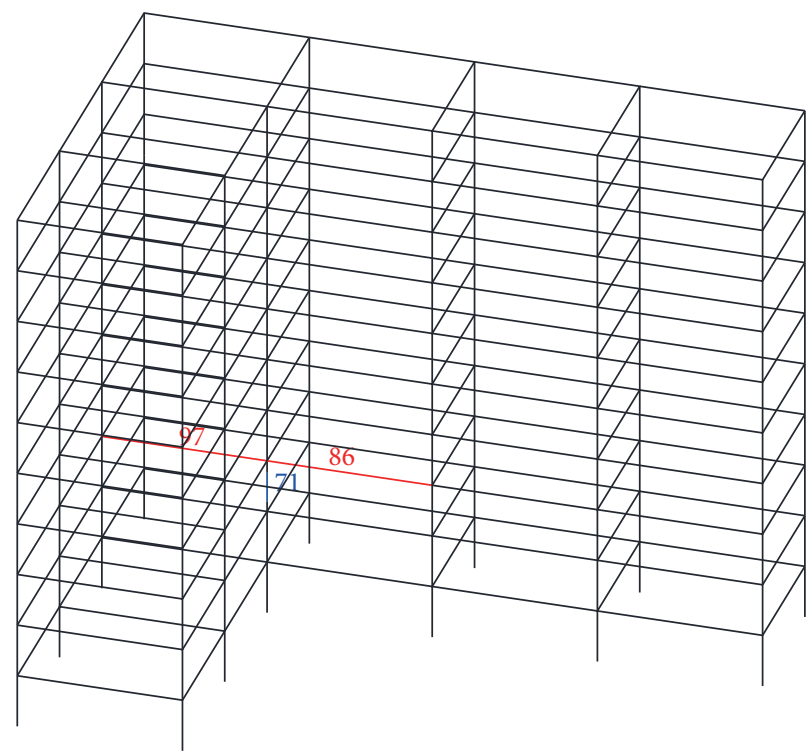

FIGURE 21: Schematic representation of indicated damaged elements in D1 using incomplete mode shapes.

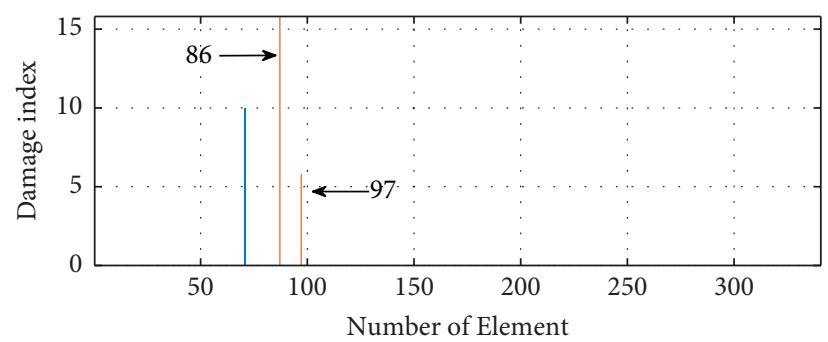

True Damage

DI

FIgURE 22: Results of damage scenario D1 using incomplete mode shapes.

both cases with $10 \%$ noise, the plots indicate the damaged element and the damage in the column element connected to and in the upper level of the damaged element. This is reasonable as these elements are connected to the damaged element, and they will exhibit some damage characteristics in the mode shape data at the shared nodes. The effects of 


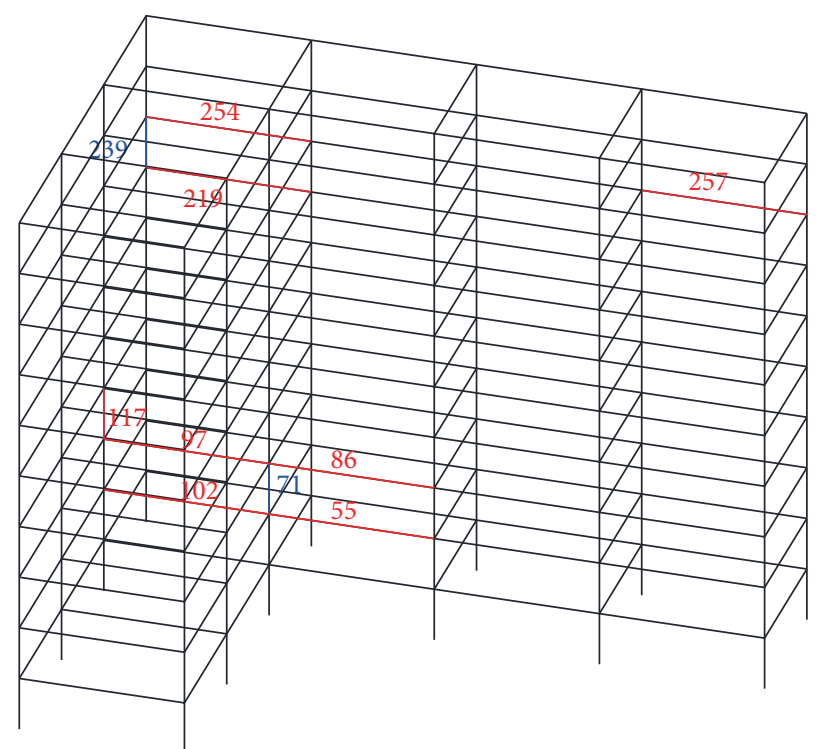

FIgURE 23: Schematic representation of indicated damaged elements in D5 using incomplete mode shapes.

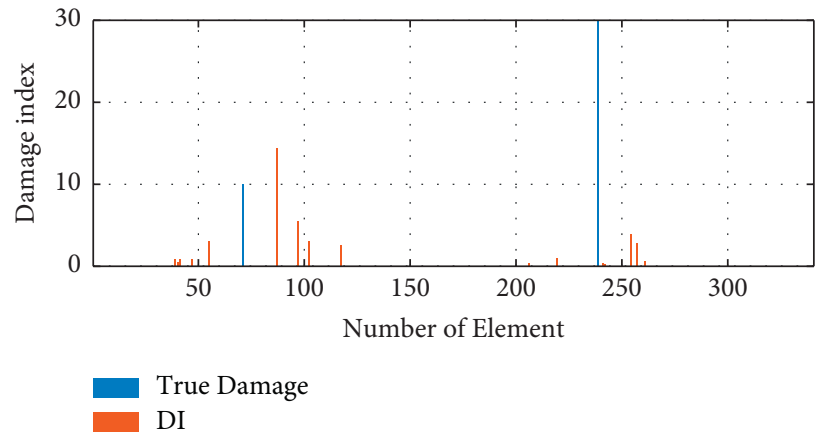

FIGURE 24: Results of damage scenario D5 using incomplete mode shapes.

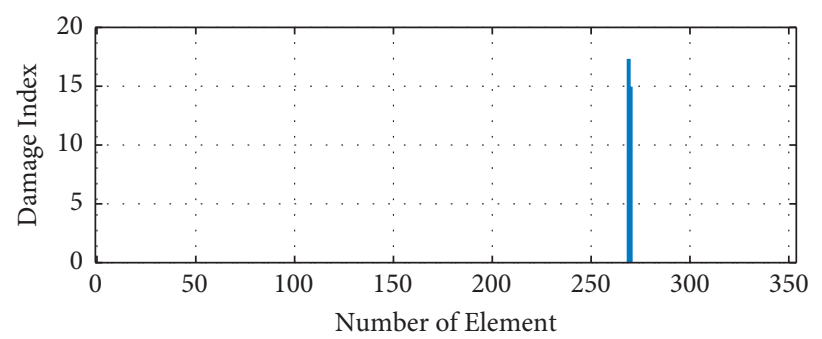

FIGURE 25: Results of single damage case D1 using MCA-DI (setback building).

random noise on the damage detection capability of the proposed method can be reduced by considering fewer modes in the calculation of the MCA-DI. As seen from Figures 19 and 20, when only the first 3 modes are used in the calculation of the proposed MCA-DI, the effect of large noise levels could be effectively reduced. This feature further demonstrates the fact that higher modes are more sensitive to the measurement noise and the capability of the proposed method in damage detection with only the first 3 modes in the complicated building structures.

(2) Results of Incomplete Mode Shapes. As we know, a bridge structure normally can be considered as a single large element and damage detection in the absence of complete modal data is not normally difficult. If there is no sensor information at the damaged location, the damage could yet 


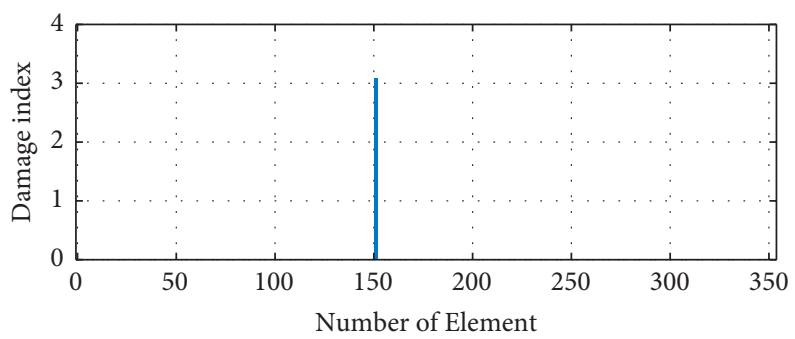

Figure 26: Results of single damage case D2 using MCA-DI (setback building).

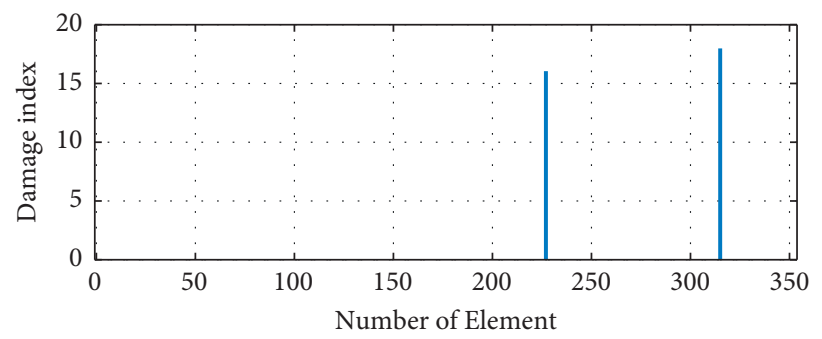

FIGURE 27: Results of multidamage case D3 using MCA-DI (setback building).

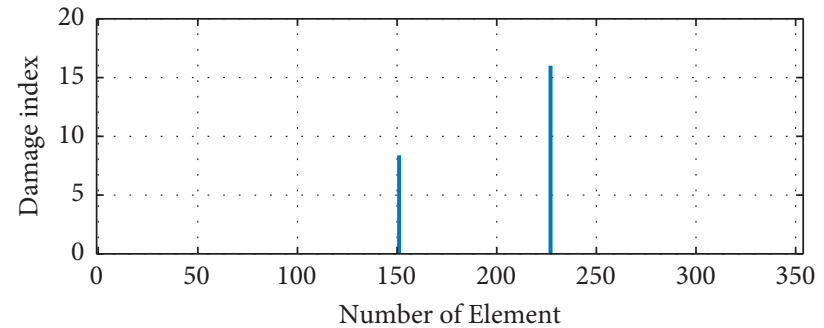

FIgURE 28: Results of multidamage case D4 using MCA-DI (setback building).

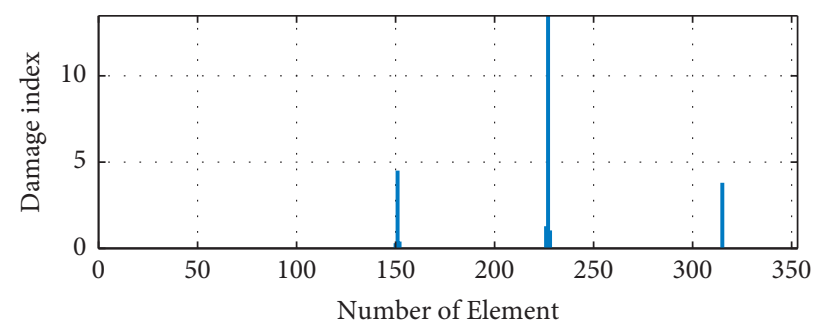

FIgURE 29: Results of multidamage case D5 using MCA-DI (setback building).

be located by plotting the trend between sensors. However, for asymmetric buildings, due to the $3 \mathrm{D}$ features, the structural members are in a different direction, such as the beams in two mutually perpendicular horizontal directions while columns are in the vertical direction. This makes it very difficult to accurately predict the damage location if there is no information (no sensor) from the damaged member. But since damage could affect the members connect or near the actually damaged elements, it could yet be captured by the nearest sensors attached to the structure.
As seen from Figure 21, there will be no information on the plot damaged element 71 since we deliberately removed this. The indicated damaged elements are those members connected to or near the damaged element, as seen from Figure 22. If a polynomial is fitted across the MCA-DI values, they will more or less point to the actually damaged column element. This demonstrates that even when there is no information directly on the damaged element, the proposed method could still locate damage, at least the damaged region. Results for the multiple-damage scenario D5 also 


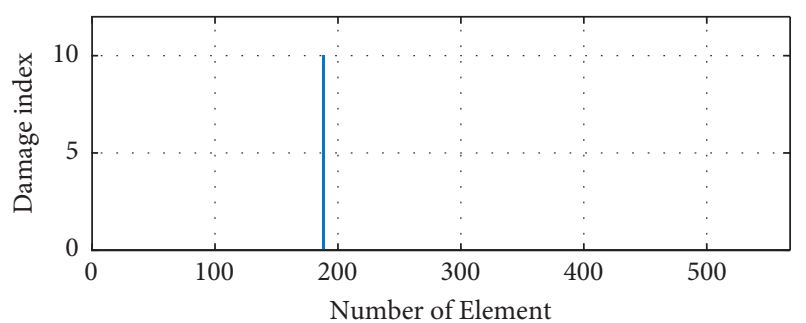

Figure 30: Results of single-damage case D1 using MCA-DI (building with the unsymmetrical distribution of columns).

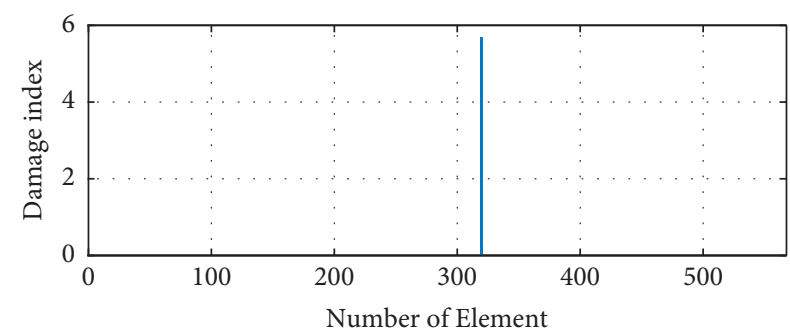

FIgURE 31: Results of single-damage case D2 using MCA-DI (building with the unsymmetrical distribution of columns).

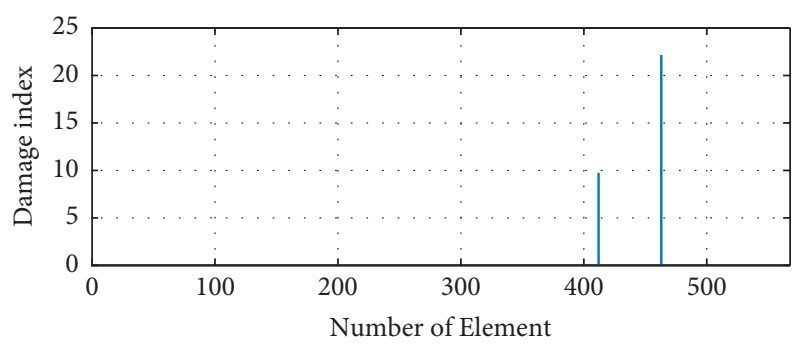

Figure 32: Results of multidamage case D3 using MCA-DI (building with the unsymmetrical distribution of columns).

confirm this feature, as shown in Figures 23 and 24. Although elements 257 and 261 are indicated in the results, which seems quite far from damaged element 239, the previous study provided that due to torsional coupling, the damage tends to propagate to the other element [35]. And since the corner elements are easier to be affected [45], it is reasonable to show a large value in elements 257 and 261. Hence the proposed method is able to locate the damage through the information provided by these nearby sensors. In this case, the proposed method shows good capability in locating the damaged region using incomplete mode shapes that do not have any information on the damaged member.

3.3.2. Setback Building. Figures 25 and 26 show the results of single damage cases using the MCA-DI method. For the first single damage case $\mathrm{D} 1$, the results show that the damage is in elements 269 and 270 by the MCA-DI method. As discussed earlier, since column element 270 is connected to element 269 , it is reasonable for element 270 to get a high DI as well. As to the second single damage case D2, excellent results are

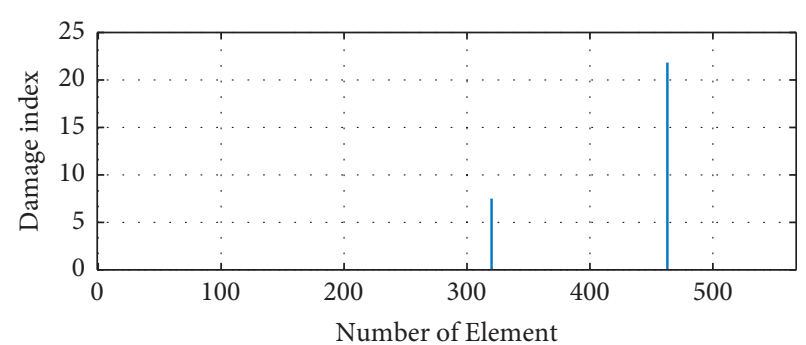

FIgURE 33: Results of multidamage case D4 using MCA-DI (building with the unsymmetrical distribution of columns).

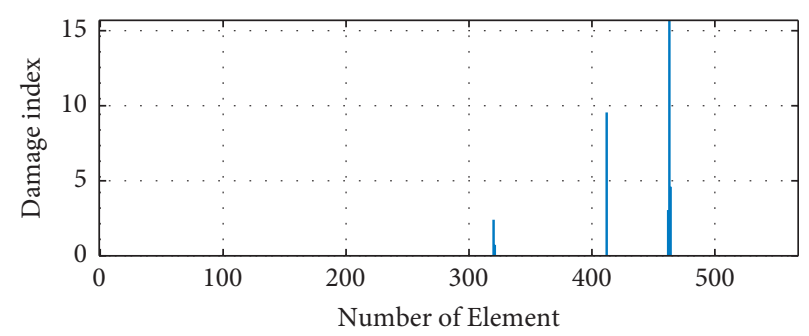

FIgUre 34: Results of multidamage case D5 using MCA-DI (building with the unsymmetrical distribution of columns).

obtained by the MCA-DI method, which accurately predicts the damage location.

The cases D3-D5 investigate the damage detection for multidamage locations. For the first double damage case D3 (Figure 27), the MCA-DI method correctly predicts the locations of both damaged elements. It is found that the damage extents predicted for the beam element are more accurate than for the column element. This aspect has also been found in a previous study [35], in which the structure studied has a simpler form. The proposed method also correctly predicts the locations of the damages of the second double damage case D4 (Figure 28). For the triple damages case D5 (Figure 29) which pertains to damage in 3 members, the results of damages turn out to correctly locate at 2 beams and 1 column. Besides, the damage severities are underestimated, especially that in the column element.

\subsubsection{Building with Unsymmetrical Distribution of Columns.} The damage localization results using MCA-DI with complete mode shapes for the building with the unsymmetrical distribution of columns are shown in Figures 30-34. It is evident that in all damage scenarios, the damage sites can be determined by the proposed MCA-DI. However, damage severities are not well estimated, especially when damage is in the column element in multidamage cases.

\section{Conclusions}

This paper developed and applied the method Multicriteria Approach based Damage Index (MCA-DI) that is capable of detecting damage in 3D asymmetric buildings, regardless of the type of asymmetry. It treated three different types of 
asymmetric buildings to investigate the feasibility of detecting structural damage using the proposed method, and the following conclusions are drawn:

(1) Even though these three different types of asymmetric building structures presented different vibration characteristics, the proposed MCA-DI method is able to accurately and effectively locate structural damage and eliminate confusion when more than one index is simultaneously used.

(2) Mode shape with 3\% noise has no adverse effects in detecting damage in both single and multipledamage cases, while when noise is increased to $5 \%$ level, the damage is also indicated in the column elements connect to the damaged column element in the upper level. This trend is also evident in the results with the larger $10 \%$ noise in the modal data. The approach of reducing the number of modes in the calculation of the MCA-DI can effectively address this problem as evidenced by the results using only the first 3 modes in calculation with 10\% noise level. Hence, we can say that the proposed MCA-DI demonstrates good capability in damage localization with up to $10 \%$ measurement noise.

(3) The results of incomplete mode shapes showed that when there is no sensor on the damaged member, the damage information could be captured by the nearest sensors. Hence, it is shown that the proposed method is able to locate the damage through the information provided by these nearby sensors. In this case, the proposed method shows good capability in locating the damaged region using incomplete mode shapes. However, the scenarios used to study the incomplete mode shapes may not be practical in reality since only the information of damaged elements was removed. The scenarios with a limited number of available sensors will be considered in future studies.

(4) The proposed method also performed well by using only the first few modes for detecting damage in 3D structures such as the asymmetric buildings treated in this study. The method developed in this paper can be extended to other structures such as high-rise buildings and multipurpose towers.

\section{Data Availability}

Data are available from the corresponding author upon request.

\section{Disclosure}

The authors guarantee that this article has never been published before and is not under consideration for publication elsewhere, and the work described in the article is original.

\section{Conflicts of Interest}

The authors declare that they have no conflicts of interest.

\section{Authors' Contributions}

All the authors have approved the manuscript that is enclosed.

\section{Acknowledgments}

The authors gratefully acknowledge the financial support of this research provided by the Queensland University of Technology. The authors also gratefully acknowledge the support from the National Natural Science Foundation of China (Grant no. 51808298), the Jiangsu Construction System Science and Technology Project (Grant nos. 2019ZD013 and 2019ZD017), and the Nantong Science and Technology Bureau (Grant no. JC2020124).

\section{References}

[1] F. Michalis, V. Dimitrios, and P. Manolis, "Evaluation of the influence of vertical irregularities on the seismic performance of a nine-storey steel frame," Earthquake Engineering \& Structural Dynamics, vol. 35, no. 12, pp. 1489-1509, 2006.

[2] S. Varadharajan, V. Sehgal, and B. Saini, "Review of different structural irregularities in buildings," Journal of Structural Engineering, vol. 39, pp. 393-418, 2012.

[3] L. Dowling and G. Rummey, Guidelines for Bridge Management: Structure Information, Bridges Publications, Los Angeles, CA, USA, 2004.

[4] T. H. Chan, K. Wong, Z. Li, and Y.-Q. Ni, Structural Health Monitoring for Long Span Bridges: Hong Kong Experience and Continuing onto Australia, pp. 1-32, Nova Science Publishers, New York, NY, USA, 2011.

[5] D. Balageas, C.-P. Fritzen, and A. Güemes, Structural Health Monitoring, Vol. 493, Wiley Online Library, Hoboken, NJ, USA, 2006.

[6] H. W. Shih, D. P. Thambiratnam, and T. H. T. Chan, "Damage detection in truss bridges using vibration based multi-criteria approach," Structural Engineering \& Mechanics, vol. 39, no. 2, pp. 187-206, 2011.

[7] P. F. Rizos, N. Aspragathos, and A. D. Dimarogonas, "Identification of crack location and magnitude in a cantilever beam from the vibration modes," Journal of Sound and Vibration, vol. 138, no. 3, pp. 381-388, 1990.

[8] J.-C. Hong, Y. Y. Kim, H. C. Lee, and Y. W. Lee, "Damage detection using the Lipschitz exponent estimated by the wavelet transform: applications to vibration modes of a beam," International Journal of Solids and Structures, vol. 39, no. 7, pp. 1803-1816, 2002.

[9] H. W. Shih, D. P. Thambiratnam, and T. H. T. Chan, "Vibration based structural damage detection in flexural members using multi-criteria approach," Journal of Sound and Vibration, vol. 323, no. 3-5, pp. 645-661, 2009.

[10] P. Cornwell, S. W. Doebling, and C. R. Farrar, "Application of the strain energy damage detection method to plate-like structures," Journal of Sound and Vibration, vol. 224, no. 2, pp. 359-374, 1999.

[11] T. Y. Hsu, Y. C. Shih, and Q.-V. Pham, "Damage detection of a thin plate using modal curvature via macrostrain measurement," Earthquake Engineering and Engineering Vibration, vol. 18, no. 2, pp. 409-424, 2019.

[12] A. Messina, T. Contursi, and E. J. Williams, "A multipledamage location assurance criterion based on natural 
frequency changes," Journal of Vibration and Control, vol. 4, pp. 619-633, 1998.

[13] K.-C. Chang and C.-W. Kim, "Modal-parameter identification and vibration-based damage detection of a damaged steel truss bridge," Engineering Structures, vol. 122, pp. 156-173, 2016.

[14] C. B. Smith and E. M. Hernandez, "Non-negative and sparsity constrained inverse problems in damage identification application to a full-scale 3D truss," Mechanical Systems and Signal Processing, vol. 140, Article ID 106648, 2020.

[15] M. Huang, W. Zhao, J. Gu, and Y. Lei, "Damage identification of a steel frame based on integration of time series and neural network under varying temperatures," Advances in Civil Engineering, vol. 2020, Article ID 4284381, 15 pages, 2020.

[16] M. Betti, L. Facchini, and P. Biagini, "Damage detection on a three-storey steel frame using artificial neural networks and genetic algorithms," Meccanica, vol. 50, no. 3, pp. 875-886, 2015.

[17] S. Wang, J. Zhang, J. Liu, and F. Liu, "Comparative study of modal strain energy based damage localization methods for three-dimensional structure," in The Twentieth International Offshore and Polar Engineering Conference, International Society of Offshore and Polar Engineers, Beijing, China, 2010.

[18] F. Liu, H. Li, W. Li, and B. Wang, "Experimental study of improved modal strain energy method for damage localisation in jacket-type offshore wind turbines," Renewable Energy, vol. 72, pp. 174-181, 2014.

[19] A. Khosravan, B. Asgarian, and H. R. Shokrgozar, "Improved Modal Strain Energy Decomposition Method for damage detection of offshore platforms using data of sensors above the water level - ScienceDirect," Ocean Engineering, vol. 219, Article ID 108337, 2020.

[20] H. W. Shih, D. P. Thambiratnam, and T. H. T. Chan, "Damage detection in slab-on-girder bridges using vibration characteristics," Structural Control and Health Monitoring, vol. 20, no. 10, pp. 1271-1290, 2013.

[21] B. Zhang, Y. Qian, Y. Wu, and Y. B. Yang, "An effective means for damage detection of bridges using the contact-point response of a moving test vehicle," Journal of Sound and Vibration, vol. 419, pp. 158-172, 2018.

[22] Z. Hu, Z. Xiang, and Q. Lu, "Passive Tap-scan damage detection method for beam structures," Structural Control and Health Monitoring, vol. 27, Article ID e2510, 2020.

[23] M. M. M. Ahmed, S. E. Abdel Raheem, M. M. Ahmed, and A. G. A. Abdel Shafy, "Irregularity effects on the seismic performance of L-shaped multi-story buildings," JES. Journal of Engineering Sciences, vol. 44, no. 5, pp. 513-536, 2016.

[24] A. V. Kazim, S. F. Anwar, and M. Hashmath, "Seismic analysis of irregular (L-Shaped) RCC building," Journal of Research, vol. 2, 2017.

[25] B. Khanal and H. Chaulagain, "Seismic elastic performance of L-shaped building frames through plan irregularities," Structure, vol. 27, pp. 22-36, 2020.

[26] J.-L. Lin, C.-C. Tsaur, and K.-C. Tsai, "Two-degree-of-freedom modal response history analysis of buildings with specific vertical irregularities," Engineering Structures, vol. 184, pp. 505-523, 2019.

[27] P. Giannakouras and C. Zeris, "Seismic performance of irregular RC frames designed according to the DDBD approach,” Engineering Structures, vol. 182, pp. 427-445, 2019.

[28] S.-C. Kuok and K.-V. Yuen, "Structural health monitoring of a reinforced concrete building during the Severe Typhoon Vicente," Science World Journal, vol. 2013, Article ID 509350, 12 pages, 2012.
[29] H. Li, H. Sun, B. Song, D. Zhang, X. Shang, and D. Liu, "Nonlinear dynamic response of an L-shaped beam-mass piezoelectric energy harvester," Journal of Sound and Vibration, vol. 499, Article ID 116004, 2021.

[30] G. Arslan, M. Borekci, B. Sahin, M. I. Denizer, and K. S. Duman, "Performance evaluation of in-plan irregular RC frame buildings based on Turkish seismic code," International Journal of Civil Engineering, vol. 16, no. 3, pp. 323-333, 2018.

[31] R. Omrani, R. E. Hudson, and E. Taciroglu, "Story-by-story estimation of the stiffness parameters of laterally-torsionally coupled buildings using forced or ambient vibration data: II. Application to experimental data," Earthquake Engineering \& Structural Dynamics, vol. 41, no. 12, pp. 1635-1649, 2012.

[32] G. Bernagozzi, C. E. Ventura, S. Allahdadian, Y. Kaya, L. Landi, and P. P. Diotallevi, "Output-only damage diagnosis for plan-symmetric buildings with asymmetric damage using modal flexibility-based deflections," Engineering Structures, vol. 207, Article ID 110015, 2020.

[33] M. R. Kaloop and J. W. Hu, "Damage identification and performance assessment of regular and irregular buildings using wavelet transform energy," Advances in Materials Science and Engineering, vol. 2016, Article ID 6027812, 11 pages, 2016.

[34] J.-F. Wang, C.-C. Lin, G.-L. Lin, and C.-H. Yang, "Story damage identification of irregular buildings based on earthquake records," Earthquake Spectra, vol. 29, no. 3, pp. 963-985, 2013.

[35] Y. Wang, D. P. Thambiratnam, T. H. T. Chan, and A. Nguyen, "Method development of damage detection in asymmetric buildings," Journal of Sound and Vibration, vol. 413, pp. 4156, 2018.

[36] N. Stubbs and J.-T. Kim, "Damage localization in structures without baseline modal parameters," AIAA Journal, vol. 34, no. 8, pp. 1644-1649, 1996.

[37] M. López-Aenlle, P. Fernández, R. Brincker, and A. Fernández-Canteli, "Scaling-factor estimation using an optimized mass-change strategy," Mechanical Systems and Signal Processing, vol. 24, no. 5, pp. 1260-1273, 2010.

[38] H. Li, H. Yang, and S.-L. J. Hu, "Modal strain energy decomposition method for damage localization in 3D frame structures," Journal of Engineering Mechanics, vol. 132, no. 9, pp. 941-951, 2006.

[39] Y. Wang, D. P. Thambiratnam, T. H. T. Chan, and A. Nguyen, "Damage detection in asymmetric buildings using vibrationbased techniques," Structural Control and Health Monitoring, vol. 25, no. 5, Article ID e2148, 2018.

[40] W. R. Wickramasinghe, D. P. Thambiratnam, T. H. T. Chan, and T. Nguyen, "Vibration characteristics and damage detection in a suspension bridge," Journal of Sound and Vibration, vol. 375, pp. 254-274, 2016.

[41] Ansys Inc, ANSYS Mechanical APDL Academic Research, Ansys.Inc, Canonsburg, PA, USA, 2011.

[42] A. Messina, I. Jones, and E. Williams, "Damage detection and localization using natural frequency changes," in Proceedings of conference on Identification in Engineering Systems, Cambridge, UK, 1996.

[43] C. R. Farrar and K. M. Cone, Vibration Testing of the I-40 Bridge before and after the Introduction of Damage, Los Alamos National Lab., Santa Fe, NM, USA, 1994.

[44] Z. Y. Shi, S. S. Law, and L. M. Zhang, "Damage localization by directly using incomplete mode shapes," Journal of Engineering Mechanics, vol. 126, no. 6, pp. 656-660, 2000.

[45] J.-L. Lin and K.-C. Tsai, "Simplified seismic analysis of asymmetric building systems," Earthquake Engineering \& Structural Dynamics, vol. 36, no. 4, pp. 459-479, 2007. 